\title{
Enhancement of blast resistance of R.C beams using micro/nano silica in the presence of steel fibers
}

\author{
Mahmoud T. Nawar, Kareem A. El-Awady, Hamdy K. Shehab, Ahmed S. Eisa \\ Zagazig University, Department of Structural Engineering, Egypt. \\ Mn6w8@mail.missouri.edu,k_abmed2012@hotmail.com
}

\begin{abstract}
The study investigates the effect of Micro/Nano silica and steel fibers on improving the dynamic response of R.C beams, using the ABAQUS/Explicit dynamic analysis. According to the results of Magnusson and Hallgren's experimental investigation, the FE model has been wellverified and calibrated. The FE test program has further been extended to study the effect of tensile reinforcement ratios $\boldsymbol{\mu}$ of $0.5 \%, 0.78 \%$, and $1.13 \%$, in comparison with the enhancement of concrete's material properties, on the behavior of tested beams under blast loading. The results were compared in terms of changes in the max deflection at mid-span and flexural toughness values. The results showed that the flexural toughness of beams decreases when the tensile reinforcement ratio increases due to an increase in the moment of inertia ( $\left.\mathrm{I}_{\text {effective }}\right)$.R.C beams incorporating SMCs $(10 \% \mathrm{MS}+1 \% \mathrm{NS})$ with different volume fractions $(0 \%, 1 \%, 2 \%)$ of steel fibers showed that the concrete mixes with higher compressive strength values lead to an increase in the last beam deflection, producing a considerable rise in the flexural toughness by $18.2 \%, 27 \%$ and $31.8 \%$ for $\boldsymbol{\mu}(0.50 \%)$ and $15 \%, 19.9 \%$ and $23.6 \%$ for $\boldsymbol{\mu}(0.78 \%)$ and $6.6 \%, 13.7 \%$ and $19.6 \%$ for $\boldsymbol{\mu}(1.13 \%)$ respectively in comparison with the reference beam.
\end{abstract}

KEYWORDS. Reinforced concrete; Micro silica; Nano silica; Blast load; Flexural toughness; Steel fibers.

\section{OPEN ACCESS}

Citation: Nawar, M., El-Awady, K., Shehab, H., Eisa, A., Enhancement of blast resistance of R.C beams using micro/nano silica in the presence of steel fibers, Frattura ed Integrità Strutturale, 57 (2021) 259-280.

Received: 20.04 .2021

Accepted: 10.06 .2021 Published: 01.07.2021

Copyright: (C) 2021 This is an open access article under the terms of the CC-BY 4.0, which permits unrestricted use, distribution, and reproduction in any medium, provided the original author and source are credited.

\section{INTRODUCTION}

$\mathrm{B}$ last loads are considered one of the severe loads impacting structures, and even a small amount of blast may cause significant damage to the structure, Baker et al. [1].Enhancement of the ductility and flexural toughness of concrete material plays an important role in absorbing much more energy of R.C structural elements, not only under static loads but also dynamic loads such as "blast" . Ductility refers to the ability of material to undergo plastic deformation without failure. On the other hand, toughness refers to the energy required to deform a material to failure. Tough materials tend to have both high strength and significant deformation before failure. In case of a blast pressure 
resulting from an explosion, the equation of motion under dynamic loads can be generalized as shown in Eqn. 1. the dynamic response in terms of deflection y can be predicted by various numerical procedures (Biggs 1964) [2].

$$
\mathbf{F}(\mathbf{t})=\mathrm{M} \mathrm{y}^{\prime \prime}+\mathrm{R}
$$

where, the mass $(\mathrm{M})$, the static resistance $(\mathrm{R})$, and the applied load function of time $(\mathrm{F}(\mathrm{t}))$ are the parameters for the equation of motion.

Therefore, the static resistance of the structural system has a main role in predicting the dynamic response to blast loads. The challenge is to expand the static response limit and increase the limits of ductility.

According to Magnusson [3], ductility and structural stiffness have a significant impact on the failure mode of R.C beams under blast loading. That is, when R.C beams with various reinforcement ratios are exposed to blast loads, only beams with the low reinforcement ratio fail in flexure; and when the reinforcement ratio increases, the failure mode changes into a brittle shear failure. Therefore, the sudden shear failures can be avoided by designing structural components that are less stiff and, hence, more ductile.

Several codes such as UFC [4] and FKR [5] indicate that the ratio of longitudinal reinforcement and the yield strength of a structure should be representative of its capacity to withstand a blast load. When considering extreme dynamic loads, it is important to design ductile elements that can withstand significant plastic deformations, and brittle modes of failure must be avoided [4]. Fig. 1 shows the typical behavior of a brittle and ductile failure mode.

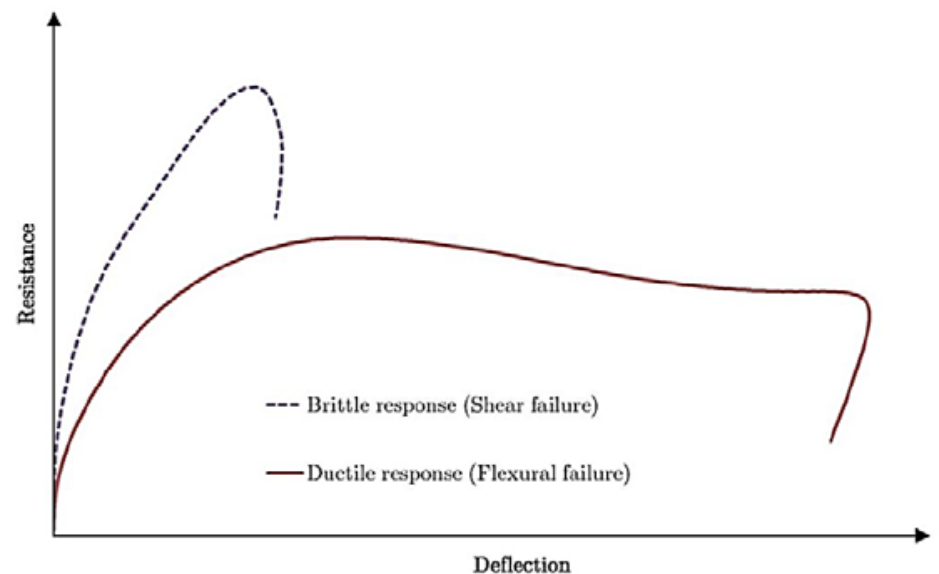

Figure 1: Schematic illustration of a brittle and ductile structural response.

In the ductile mode of response, the element may attain large inelastic deflections without complete collapse in general. The present paper focuses on introducing many ways to improve the structural element's efficiency and energy absorption against blast loads. Adding a steel plate shear wall to a dual moment-resisting frame system, this has many advantages, including high energy absorption and suitable ductility against blast loadings. Increasing stiffness and decreasing displacement have made the steel plate shear wall a proper system for retrofitting existing structures [6]. On the other hand, for R.C structures at the far design range, the applied blast load has a fairly uniform distribution, the deflections needed to absorb the loading are comparatively small, and the single leg stirrups are used as shear reinforcement in slabs and walls. This form of reinforcement will provide shear resistance [4]. For the close-in design range, the applied blast load has a non-uniform distribution, with high strength and extremely high-pressure concentrations. This, in turn, can produce a local punching failure of an element. The use of lacing reinforcement improves the ductility of the structural element significantly, protecting the concrete between the two layers of flexural reinforcement and maintaining it despite the massive cracking. Moreover, it prevents the local shear failure caused by the high intensity of the blast pressures [4]. Ductile structural elements and proper shear capacities that prevent shear failure before flexural failure are the most efficient ways to avoid progressive collapse due to the development of blast loads. So, it is an issue of high priority to enhance the ductility and flexural toughness of concrete material for R.C structural elements by developing material technologies that can meet the highest levels of the structural performance requirements. Micro and Nano silica have remained the most valuable and commonly used mineral admixture of pozzolanic materials in the concrete and cement technology [7-9]. On the other hand, addition of steel fibers with Supplementing Cementitious Materials (SCMs) improves the flexural toughness of concrete [10-15]. 
Based on previous experimental work investigated by authors [16] to study the effect of using Micro/Nano silica in the presence of steel fibers with different volumetric fractions $(0 \%, 1 \%, 2 \%)$ on the enhancement of the static response of R.C beams. The results showed that replacing cement with 1\% NS and 10\% MS provides the optimum mixture, which improves the mechanical properties and response of R.C beams under static loads significantly [16]. Furthermore, addition of steel fibers with different volume fractions has a major influence on the flexural toughness of concrete mixes. The main objective of this research is to enhance the blast resistance of R.C structural element under blast loading, depending upon the mechanical properties of the concrete material constructed from $1 \%$ NS and 10\% MS in the presence of steel fibers with different volume fractions. Furthermore, an extensive parametric study will be conducted to investigate the effect of enhanced concrete materials with different steel reinforcement ratios $\boldsymbol{\mu}(0.5 \%, 0.78 \%$, and $1.13 \%)$ on the flexural toughness behavior of R.C element under blast loading.

\section{BLAST LOADING}

A $\mathrm{n}$ explosion is described as a large-scale release of energy in a short period of time caused by chemical reactions. This rapid release of energy raises the temperature and pressure of the surrounding air. The distance available between the blast source and the target is called "stand-off distance". Since all blast parameters are dependent on the amount of energy emitted by the explosion and the distance available to a specific target from the explosion's source, a scaled distance in evaluates of explosion effects [4]. This is illustrated in cube root scaling:

$$
\mathbf{Z}=\frac{\mathrm{R}}{\mathrm{W}^{\left(\frac{1}{3}\right)}}
$$

where $Z$ is the scaled distance, $R$ is the range from the center of the charge (Stand-off distance), $\mathrm{W}$ is the mass of the spherical TNT charge equivalent.

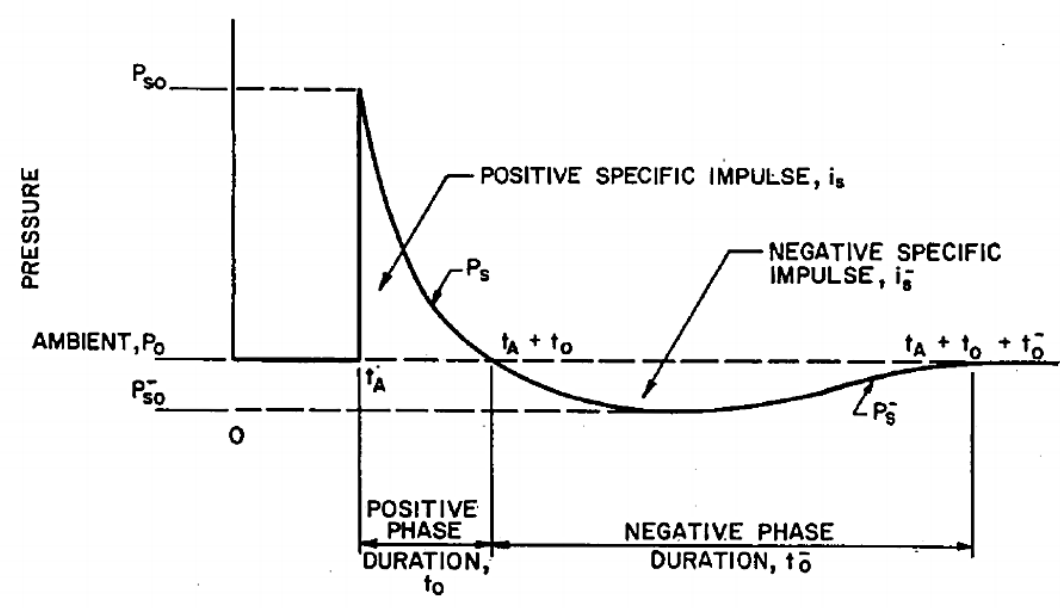

Figure 2: Overpressure- time profile.

Pressure variation at a particular point after the explosion with time is described in the overpressure time profile as shown in Fig. 2. It consists of a positive phase followed by a negative phase with different time durations [4]. The area under the curve represents the related impulse caused. A simplification of the blast wave profile is made and preserved the positive phase linear variation as shown in Fig. 3. The relationship is presented as follows:

$$
\mathbf{P}(\mathbf{t})=\mathrm{P}_{\mathrm{o}}+\mathrm{P}_{\mathrm{so}}\left(1-\frac{t}{t_{0}}\right)
$$

where $p(t)$ is the pressure at time $t, p$ so is the peak side-on overpressure, $t$ is the time measured from the instant that the blast wave arrives (at time $=t a$ ), to is the duration of the positive phase of the blast. 
This simple formula is sufficient to forecast the blast pressure as the positive phase is significant in determining the structural response. Numerical values for these parameters can be obtained from various sources in respect to the required scaled distance, $(Z)$.

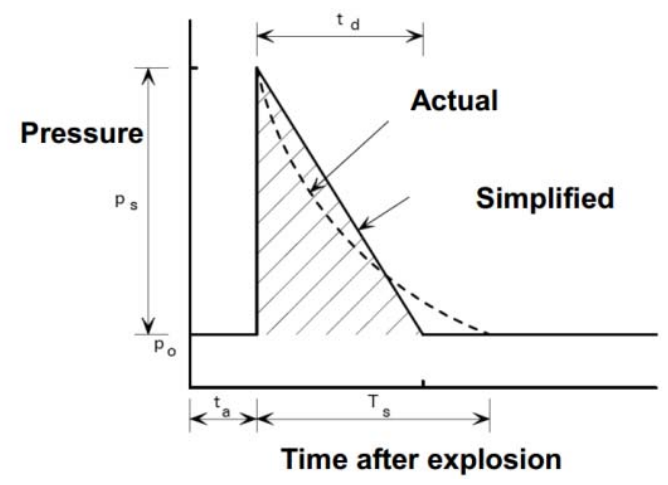

Figure 3: Simplified blast wave overpressure profile.

\section{DyNAmic ANALYSis (SDOF)}

$\mathrm{T}$ heoretical studies of the response of blast-loaded structures are sometimes difficult and highly intricate, so some simplified approaches are used for practical design objectives. Fig. 4 shows how simple structures like slabs and beams can be simplified to an equivalent single degree of freedom (SDOF) system that behaves similarly to the real element. The transformation factors are used to transform the analyzed structure to an equivalent SDOF system.
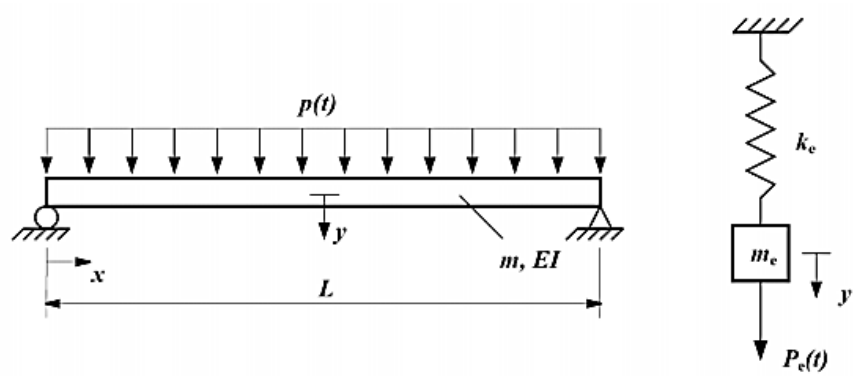

Figure 4: Beam idealized as SDOF mass and spring system.

\section{Deflection Time History}

Tab. 1 shows the transformation factors for converting a simply supported beam under uniform loads to an equivalent SDOF system in accordance with UFC [4]. Eqn. 4 can be used to measure the corresponding SDOF elastic stiffness of a simply supported beam under a uniform load.

\begin{tabular}{cccc}
\hline Range of & $\begin{array}{c}\text { Mass factor } \\
\left(\mathrm{K}_{\mathrm{M}}\right)\end{array}$ & $\begin{array}{c}\text { Load factor } \\
\left(\mathrm{K}_{\mathrm{F}}\right)\end{array}$ & $\begin{array}{c}\text { Load-Mass factor } \\
\left(\mathrm{K}_{\mathrm{MF}}\right)\end{array}$ \\
Eehavior & 0.5 & 0.64 & 0.78 \\
Elastic & 0.33 & 0.5 & 0.66 \\
Plastic & 0.42 & 0.57 & 0.72 \\
\hline
\end{tabular}

Table 1: Transformation factors for a simply supported beam under uniform loads [4].

$$
\mathbf{K}=\frac{384 \mathrm{EI}}{5 \mathrm{~L}^{3}}
$$

As the R.C beam deflects in response to a dynamic load, it goes through several stages before coming to a rest. The stiffness of the beam varies significantly across the stages as shown in Fig. 5. Magnusson [17] defines state (1) as the elastic 
stage and state (2) as a cracked beam. According to UFC [4], an approximate formula of flexural stiffness is calculated as follows:

$$
\mathbf{E I}=0.5 \mathrm{E}_{\mathrm{c}}\left(\frac{384 \mathrm{EI}}{5 \mathrm{~L}^{3}}+\alpha_{\eta \varrho} \mathrm{bd}^{3}\right)
$$

where $a_{\eta \varrho}$ is a factor that is affected by the configuration and amount of the reinforcement as well as the steel to concrete modulus of elasticity ratio [4].

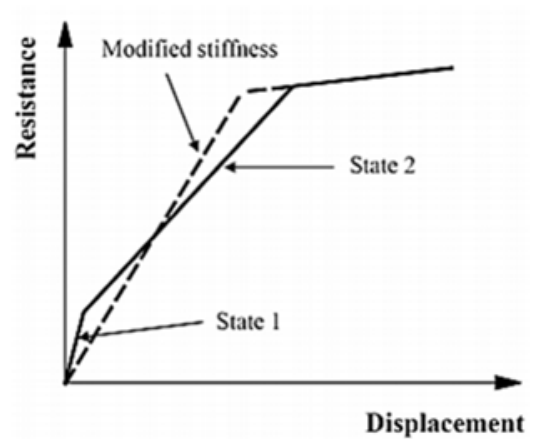

Figure 5: Schematic of the reduction in stiffness at an increasing cracking of the R.C beam with a modified stiffness [17].

The circular frequency and natural period of this equivalent SDOF system can be obtained using the Eqn. 6 . The equation of motion of the undamped SDOF system subjected to an applied force $P(\mathrm{t})$ is represented by Eqn. 7 .

$$
\begin{aligned}
& \mathbf{T}=\frac{2 \pi}{\omega}=2 \pi \sqrt{\frac{K_{M F} \cdot m}{K}} \\
& \boldsymbol{P}(\mathbf{t})=\left(K_{M F} \cdot \mathrm{m}\right) \ddot{\mathrm{y}}+\mathrm{Ky}
\end{aligned}
$$

To consider the plastic deformations that occur after the structure's initial elastic response, Fig. 6a shows how an elasticperfectly plastic resistance function can be used to simplify the element's resistance function. Fig. 6b shows how a simple triangle pulse load can be used to approximate the air blast load on a structure with reasonable accuracy.

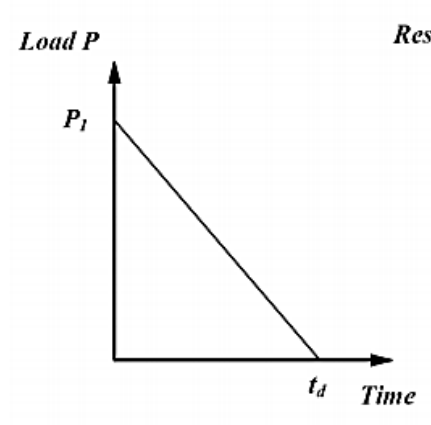

(a)

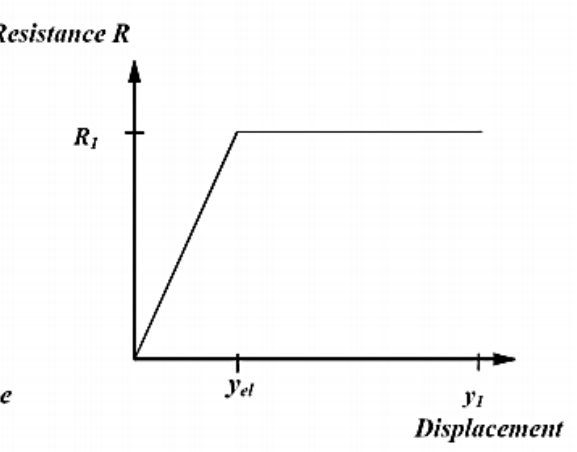

(b)

Figure 6: (a) Simplified equivalent triangular load, (b) Linear elastic-perfectly plastic resistance function of SDOF system.

As shown in Fig. 6, by using the resistance functions and simplified load, the Duhamel's integral can be used to solve Eqn. 7, Chopra [18]. Thus, the following equations can represent the deflection time history of the SDOF system up to the peak:

- The elastic stage's response, $\left(0 \leq \mathrm{t} \leq \mathrm{t}_{\mathrm{el}}\right)$ is: 


$$
\mathbf{y}=\frac{p_{1}}{k}(1-\cos (\omega \mathrm{t}))+\frac{p_{1}}{k \cdot t_{d}}\left(\frac{\sin (\omega t)}{\omega}-1\right)
$$

- The plastic range response up to the peak, $\left(t_{\mathrm{el}} \leq \mathrm{t} \leq \mathrm{t}_{\mathrm{m}}\right)$ is:

$$
\mathbf{y}=\frac{p_{1}}{6 m k_{M F} t_{d}}\left(t-t_{e l}\right)^{3}+\left(\frac{P_{1}-R_{1}}{2 m K_{M F}}-\frac{t_{e l} P_{1}}{t_{d} 2 m K_{M F}}\right)\left(t-t_{e l}\right)^{2}+y_{e l}^{\prime}\left(t-t_{e l}\right)+\mathrm{yel}_{\mathrm{el}}
$$

Several diagrams for the maximum response of SDOF systems exposed to different types of simple load functions have been developed for practical design purposes as presented in Fig. 7. The peak response can be calculated, using the ratio $(\mathrm{td} / \mathrm{T})$ and the internal resistance to the applied load ratio (R1/P1). Eqn. 10 calculates the ultimate static pressure load over a simply supported beam based on the ultimate moment capacity $\left(\mathrm{M}_{\mathrm{p}}\right)$. The ultimate moment capacity can be determined using the corresponding design code:

$$
\mathbf{q}_{\mathbf{u}}=\frac{8 M_{p}}{b L^{2}}
$$

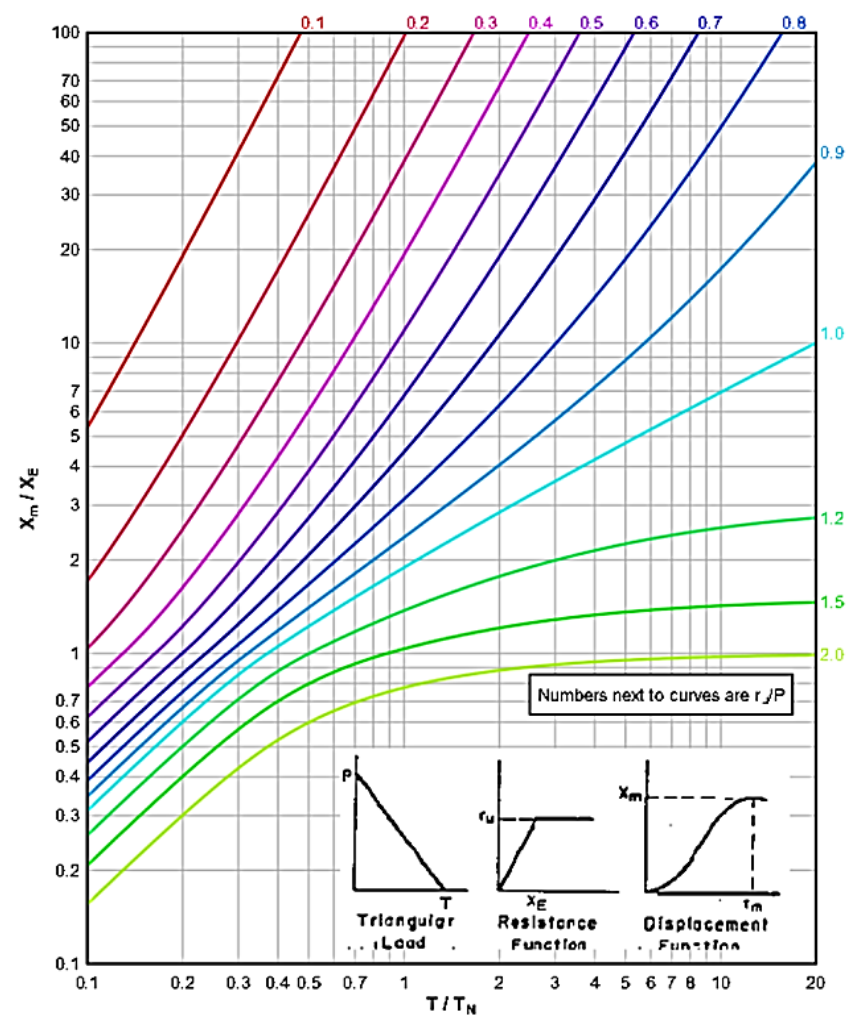

Figure 7: Max deflection of elasto-plastic, one-degree-of-freedom system for triangular load [4].
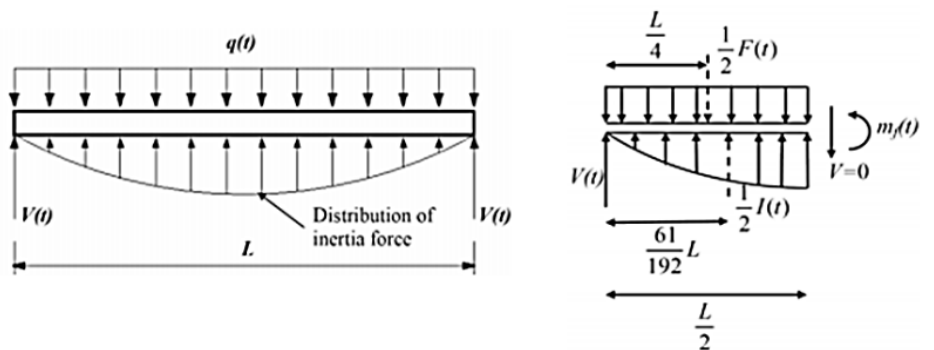

Figure 8: The dynamic reactions for a simply supported beam. 
Dynamic reaction force

The dynamic reaction forces are so important in shear design and can be estimated by taking into account the dynamic equilibrium of the real element. Fig. 8 shows a simply supported R.C beam under a uniformly distributed dynamic load. The inertia of the beam with a uniformly distributed mass follows the same pattern as the assumed deflected form as follows:

$$
V(t)=X_{R} R(t)+X_{P} P(t)
$$

\section{NumERICAL SimUlations}

$\mathrm{T}$ he deflection capacity and the dynamic flexural toughness values of R.C beams under blast loading were evaluated, using a nonlinear explicit FE model. This research used an explicit dynamic analysis based on the central difference integration rule. The explicit analysis has a major advantage over the implicit one in terms of the absence of a global tangent stiffness matrix and convergence problems [19].

\section{Verification of FE Model}

The FE model has been validated using the results of Magnusson and Hallgren's experimental investigation [3]. The results of the FE model were compared to the deflection and dynamic reaction force time histories during the verification process. It has been also important to see if the results obtained in the numerical analysis are the same as in the experiment.

Figs. 9 and 10 show the experimental setup of the shock tube test in addition to the geometry and reinforcement details of the tested R.C beam. A shock tube was used to create the air blast at (Swedish Defense Research Agency) FOI's testing ground in Märsta, which simulates blast waves. An R.C beam was bolted and nutted to the supports to keep them in place during the tests. Because of the bolts' low flexural strength, the beams were assumed to be simply supported. Furthermore, the bolt holes near the beam ends were rectangular to allow for beam movement and rotation [3].

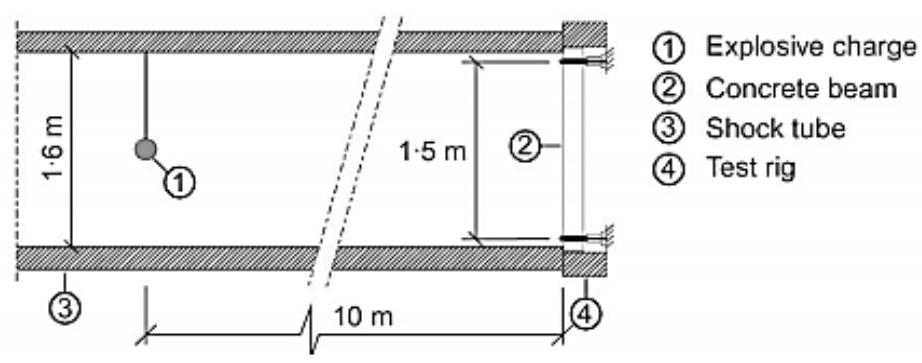

Figure 9: Experimental air blast test set up [3].

The material properties and reinforcement of the tested beam are summarized in Tab. 2. The reinforcement ratio of stirrups and spacing has been configured to prevent the shear failure. The beam was loaded with a transient uniform pressure caused by the explosive charge as showed in Fig. 9. Tab. 3 contains a summary of the air blast test results.

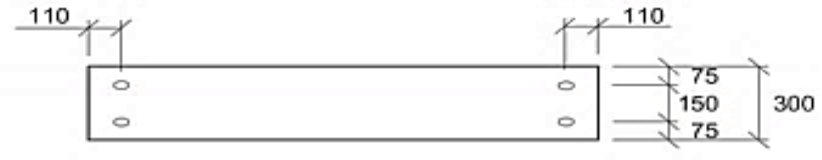

(a)

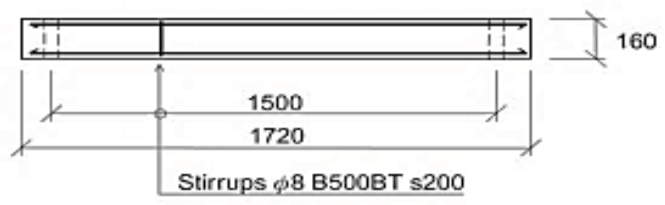

(b)

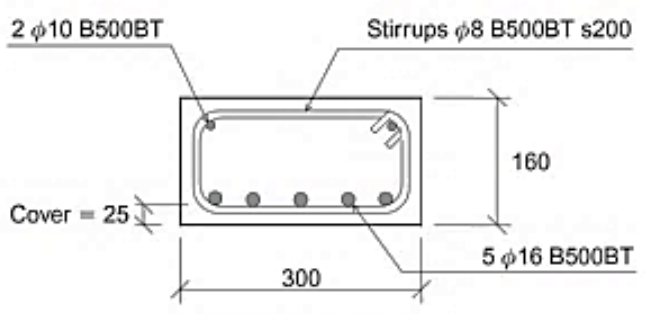

(c)

Figures 10: Geometry and reinforcement details of the tested beam. (a) Plan; (b) Elevation; (c) Cross section [3]. 


\begin{tabular}{cccccccccc}
\hline Beam Type & $\begin{array}{c}\mathrm{d} \\
(\mathrm{m})\end{array}$ & $\begin{array}{c}\mathrm{f}_{\mathrm{c}, \mathrm{cub}} \\
(\mathrm{MPa})\end{array}$ & $\begin{array}{c}\mathrm{f}_{\mathrm{sp}} \\
(\mathrm{MPa})\end{array}$ & $\begin{array}{c}\mathrm{d}_{\max } \\
(\mathrm{mm})\end{array}$ & $\begin{array}{c}\mathrm{f}_{\mathrm{y}} \\
(\mathrm{MPa})\end{array}$ & $\begin{array}{c}\varrho_{\mathrm{f}} \\
(\%)\end{array}$ & $\begin{array}{c}\mathrm{A}_{\mathrm{v}} / \mathrm{s} \\
(\mathrm{mm})\end{array}$ & $\begin{array}{c}\mathrm{s} \\
(\mathrm{m})\end{array}$ & $\begin{array}{c}\mathrm{s} / \mathrm{d} \\
\text { B40 }\end{array}$ \\
\hline 0.13 & 53.8 & 4.6 & 25 & 604 & 2.5 & 0.54 & 0.2 & 1.5 \\
\hline
\end{tabular}

Table 2: Material properties and reinforcement of tested beam.

\begin{tabular}{|c|c|c|c|c|c|}
\hline Beam Type & $\begin{array}{c}\mathrm{Q} \\
(\mathrm{kg})\end{array}$ & $\begin{array}{c}\mathrm{P} \\
(\mathrm{kPa})\end{array}$ & $\begin{array}{c}\mathrm{I} \\
(\mathrm{kPa})\end{array}$ & $\begin{array}{l}F_{\text {tot,u }} \\
(\mathrm{kN})\end{array}$ & $\begin{array}{c}\mathrm{y}_{\mathrm{m}} \\
(\mathrm{mm})\end{array}$ \\
\hline B40-D4 & 2.5 & 1249 & 6.4 & 348 & 17.5 \\
\hline
\end{tabular}

Table 3: Results of blast tests.

\section{Approximation of Pressure Loads}

The pressure-time function of the air blast test was approximated with the linear piecewise pressure-time function. Fig. 11 shows the pressure time history approximation obtained from the beam (B40-D4) test. The linear piecewise function fits the registered pressure curve well, whereas up to a period of about $10 \mathrm{~ms}$, which is the point of time corresponding to maximum deflection. Tab. 4 shows data for approximated linear piecewise pressure loads, while Tab. 5 shows data for approximated triangular pressure loads for the beam (B40-D4) analysis.

\begin{tabular}{c|ccccccccccccc}
\hline $\mathrm{t}(\mathrm{ms})$ & 0 & .07 & 1.97 & 2.87 & 4.77 & 5.42 & 7.47 & 8.17 & 9.47 & 15 & 20 & 25 \\
$\mathrm{P}(\mathrm{kPa})$ & 0 & 1170 & 610 & 710 & 410 & 500 & 250 & 380 & 210 & 100 & 45 & 0 \\
\hline
\end{tabular}

Table 4: Approximated linear piecewise pressure.

\begin{tabular}{ccc}
\hline $\mathrm{t}(\mathrm{ms})$ & 0 & 12 \\
$\mathrm{p}(\mathrm{kPa})$ & 870 & 0 \\
\hline
\end{tabular}

Table 5: Triangular pressure.
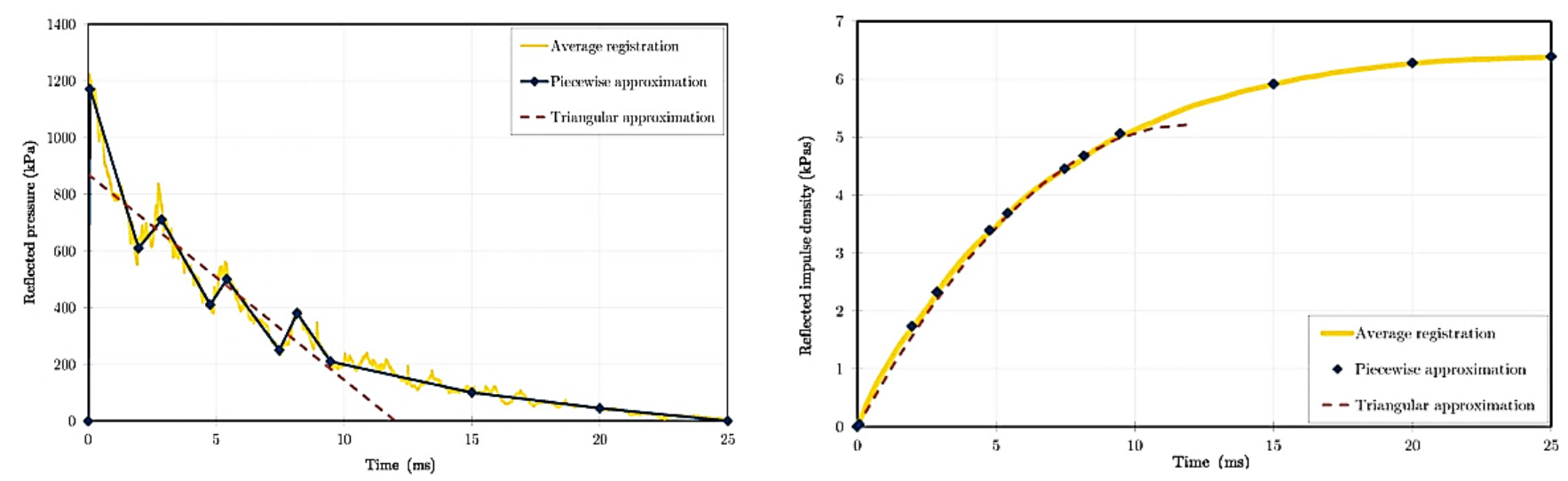

Figures 11: Piecewise linear approximation of the pressure time history of the tested beam.

The R.C beams were modeled using ABAQUS/Explicit version 6.14[19]. Fig. 12 shows the model's geometry, stirrup configuration, longitudinal reinforcement, and boundary conditions. An 8-node solid element (C3D8) was used to mesh the concrete and plates. Both stirrups and longitudinal reinforcement were discretized by a 2-node, three-dimensional truss element (T3D2). As shown in Fig. 13, the whole model was discretized with a 12.5 by 12.5 mm uniform mesh. The element sizes were chosen to be small enough to achieve convergence in the results [20]. 


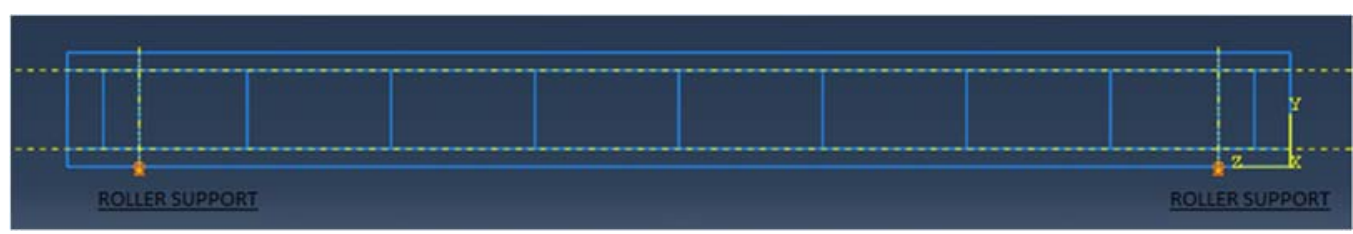

Figure 12: Geometry of a modeled beam and applied boundary conditions.

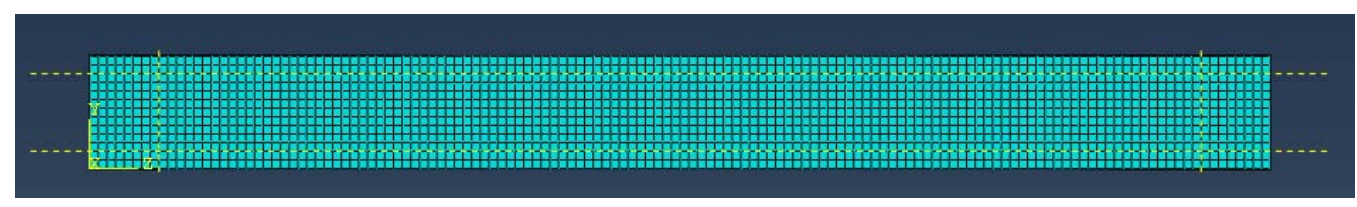

Figure 13: Meshing of R.C beam model.

To simulate the concrete behavior of beams, the Concrete Damage Plasticity (CDP) model was used according to ABAQUS Theory Manual 6.14 [19]. The CDP model is intended to analyze the overall behavior of concrete structures exposed to dynamic loads. The main failure mechanism of concrete is thought to be tension cracking and compression crushing. Figs. 14 show the simulated response of concrete to uniaxial loading in tension and compression.

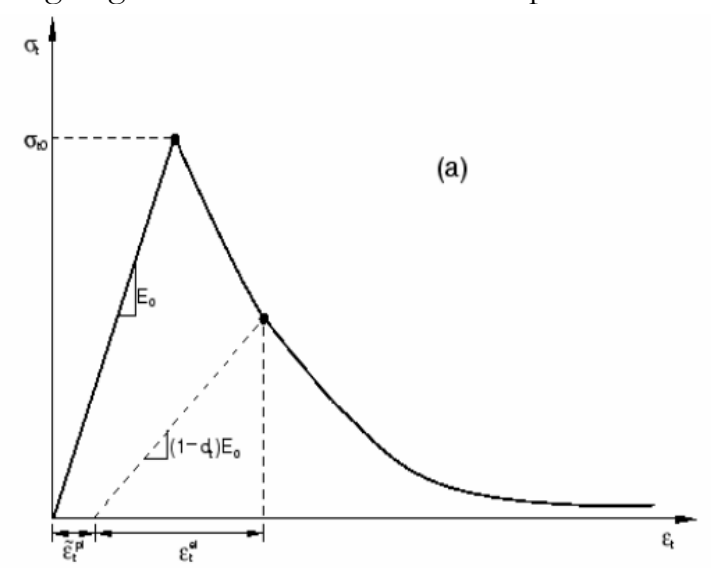

a) Stress-Strain due to tension

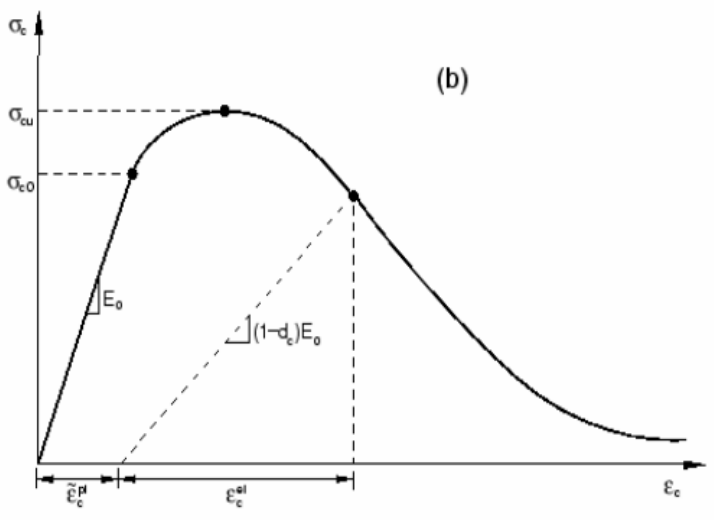

b) Stress-Strain due to compression

Figure 14: Response of concrete to uniaxial loading.

The material model CDP requires the different constants to be defined in all stages: the elasticity Stage (modulus of elasticity and Poisson's ratio), the plasticity stage (plasticity parameters, compressive behavior, tension behavior).As mentioned in the ABAQUS Theory Manual 6.14 [19] the definitions of other parameters can be outlined as follows: the dilation angle equals $30^{\circ}$ in the present study; and $\psi$ describes the performance of concrete under compound stress. The eccentricity is recommended to be assumed as 0.1 , the ratio between tensile and compressive strength. The ratio between the strength in the biaxial state and that in the uniaxial state $f_{b 0} / f_{0}$ equals 1.16 as a default value according to ABAQUS user's manual. $\mathrm{K}$ is equal to $2 / 3$ as it is typical for concrete, the ratio of the distances between the hydrostatic axis and respectively the compression meridian and the tension meridian in the deviatoric cross section. The viscosity parameter equals 0 as a default value, and it indicates the relaxation time of the viscoplastic system. The reinforcement element was assumed to be an elastic perfectly plastic material. The interface between the reinforcement and the concrete was simulated by the embedded constraint. The embedded element was steel reinforcement, and the host element was concrete.

Tabs. 6 and 7 show the properties of the steel and concrete material used in the FE model respectively. The values in these tables are derived from material test results. Tab. 7 shows the increased values due to the strain rate effect, which was calculated using Malvar and Crawford's equations [21].

Figure 15 shows the input compressive stress-inelastic strain curves for Concrete Damage Plasticity model (CDP). The scale of the time increment in the explicit dynamic analysis has a significant impact on the results. All analyses in the current simulations were carried out within a fixed time increment equal to $\Delta t=10^{-8}$. The time increment was chosen to be small enough to ensure stability in the results. 


\begin{tabular}{ccc}
\hline Mechanical properties & & Stirrups \\
Elastic modulus $(\mathrm{GPa})$ & Longitudinal Rein. & 205 \\
Poisson's ratio & 210 & 0.3 \\
Density $\left(\mathrm{t} / \mathrm{m}^{3}\right)$ & 604 & 5.85 \\
Yield stress $(\mathrm{MPa})$ & 703 & 501 \\
Ultimate stress $(\mathrm{MPa})$ & 597 \\
\hline
\end{tabular}

Table 6: Material properties of reinforcing steel for the FE model.

\begin{tabular}{ccc}
\hline Mechanical properties & Static & Dynamic* \\
Elastic modulus $(\mathrm{GPa})$ & 34.5 & 46 \\
Poisson's ratio & & 0.2 \\
Density $\left(\mathrm{t} / \mathrm{m}^{3}\right)$ & 2.40 & 56.5 \\
Compressive cylinder strength $(\mathrm{MPa})$ & 44.5 & 6.0 \\
Tensile strength $(\mathrm{MPa})$ & 4.1 & 6 \\
\hline * Strain rate $\approx 1(1 / \mathrm{sec})$ & &
\end{tabular}

Table 7: Static and dynamic properties of concrete material for the FE model

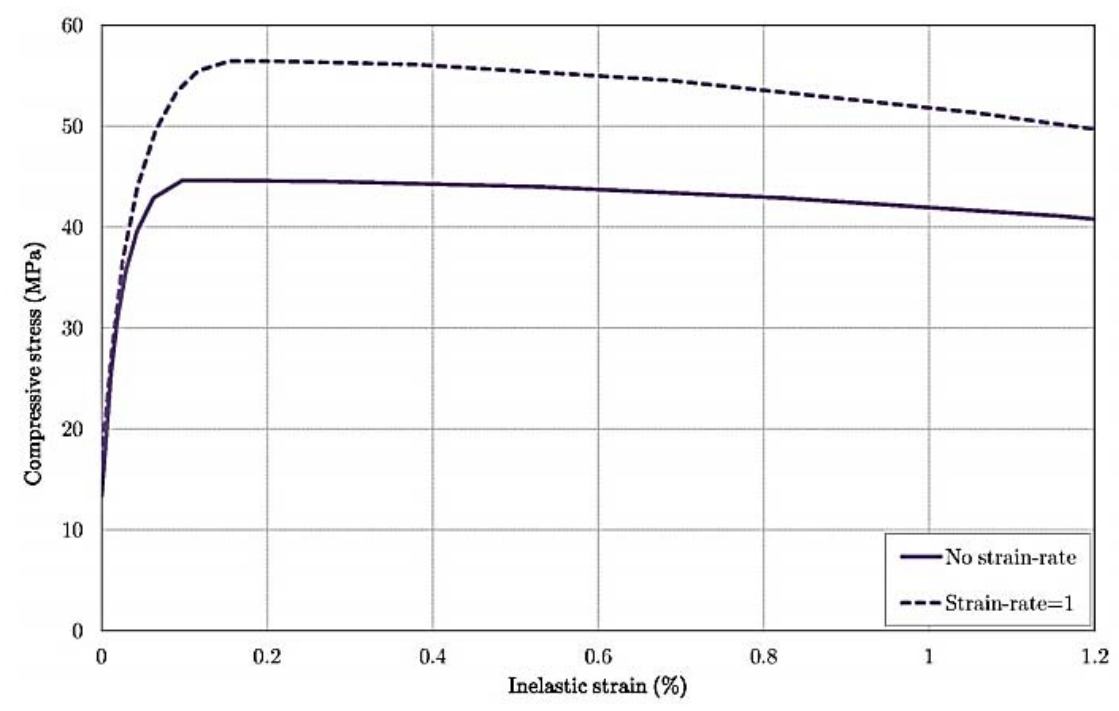

Figure 15: Input compressive stress-inelastic strain curves for concrete under different strain rates.

Verification results of the tested beam (B40-D4)

The results were compared with the calculated deflection and dynamic reaction force time histories obtained from the experimental test to determine the FE model's confidence. As previously stated, due to the simplification of support modeling, the structure's response is only accurate up to the rebound stage. Ductile failure occurred, and the steel reinforcement stress reached yielding stress first then the concrete crushes at the compression zone as illustrated by concrete compressive stress contours in Fig. 16. Fig. 17shows the concrete strain contours. 


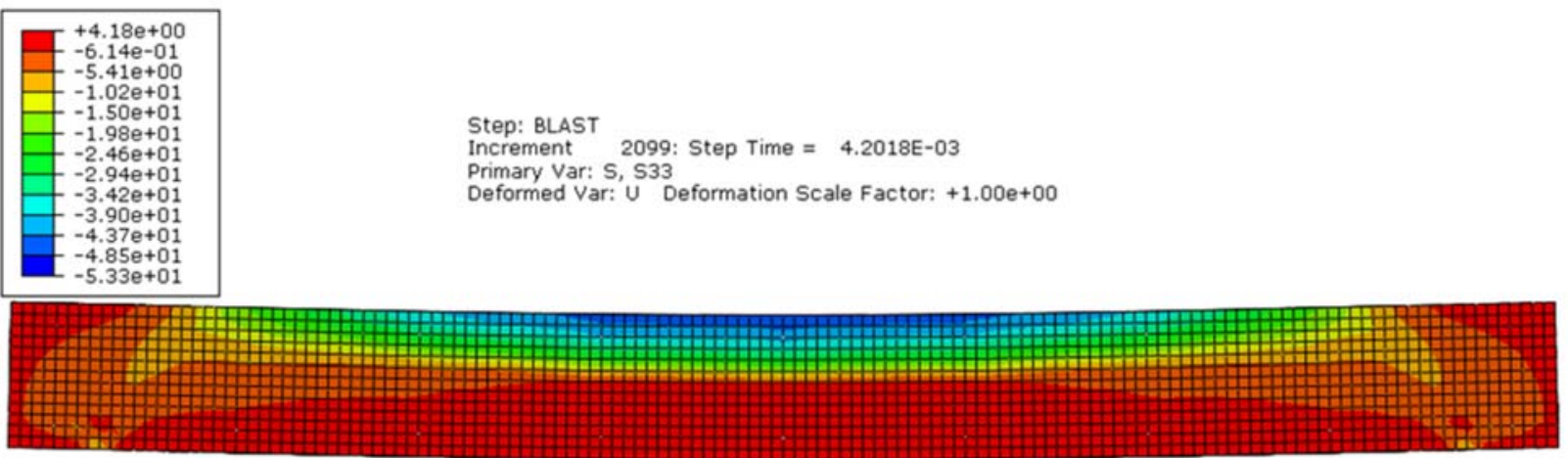

Figure 16: Concrete stress contours.

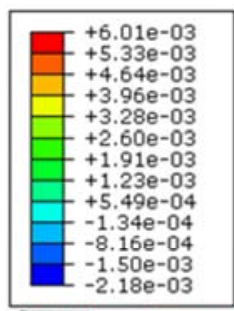

Step: BLAST

Increment 2099: Step Time $=4.2018 \mathrm{E}-03$

Primary Var: PE, PE33

Deformed Var: $U$ Deformation Scale Factor: +1.00 e+00

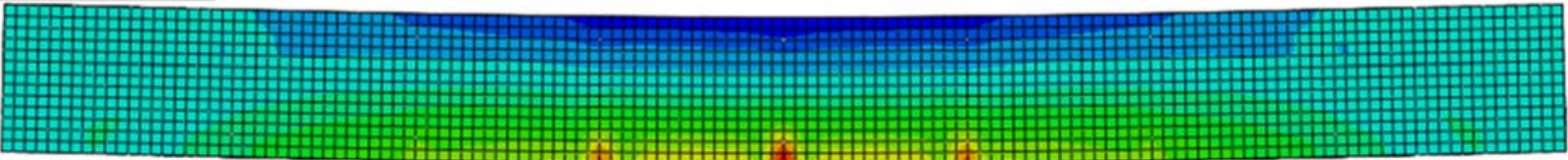

Figure 17: Concrete strain contours.

Deflection Time History

Fig. 18 shows the experiment's mid-span deflection time history, and the calibrated FE model in addition to the SDOF calculation, up to the peak response. The FE model curve has good agreement with the experimental result. The peak values of deflection obtained from the analysis and experiment are shown in Tab. 8. According to the findings, the FE model predicts the deflection response better than the SDOF calculation.

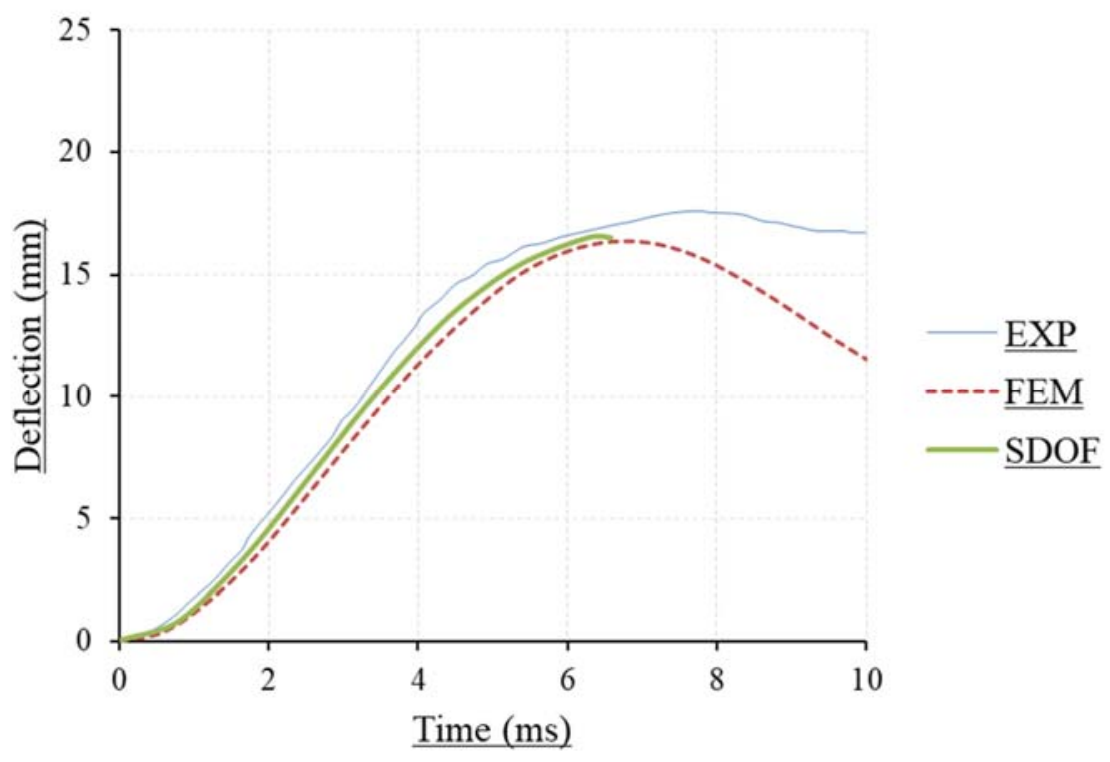

Figure 18: Mid span deflection time history of (B40-D4) beam 


\begin{tabular}{ccc}
\hline TEST & $\mathrm{y}_{\mathrm{m}}(\mathrm{mm})$ & $\mathrm{t}_{\mathrm{m}}(\mathrm{ms})$ \\
SDOF Analysis & 16.5 & 6.8 \\
EXP Test & 17.5 & 7.8 \\
FE Model & 16.3 & 7.2 \\
EXP/FEM & 1.07 & 1.08 \\
\hline
\end{tabular}

Table 8: Max.mid-span deflection and peak time.

\section{Reaction Force Time History}

Fig. 19 shows the time histories of dynamic reaction force obtained from the experiment and FE analysis. According to the findings, the trends of time histories have good agreement up to the rebound stage. The maximum reaction force and peak response time values obtained from FE analysis and experiments are shown in Tab. 9.

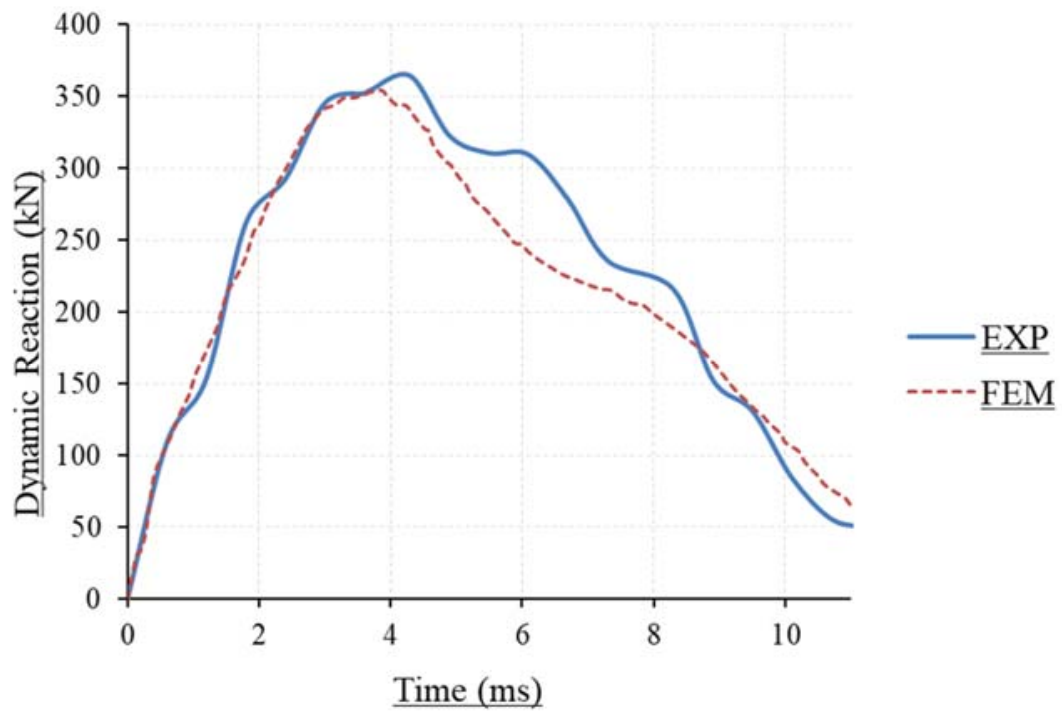

Figure 19: Dynamic reaction force time history of (B40-D4) beam.

\begin{tabular}{ccc}
\hline TEST & Dynamic Reactions $(\mathrm{kN})$ & $\mathrm{t}_{\mathrm{m}}(\mathrm{ms})$ \\
EXP-Test & 348 & 3.5 \\
FE-Model & 364 & 4.1 \\
EXP/FEM & 0.95 & 0.85 \\
\hline
\end{tabular}

Table 9: Maximum dynamic reactions and peak time values.

\section{EFFECT OF BLAST LOADING ON STUDIED R.C BEAMS}

I

$\mathrm{n}$ the present study, the finite element results using ABAQUS/Explicit are used to investigate the behavior of tested R.C beams with and without SMCs $(10 \% \mathrm{MS}+1 \% \mathrm{NS})$ in the presence of SFs with different volumetric fractions under blast loading. Tab. 10 shows a summary of mechanical properties results of tested concrete mixtures obtained from previous experimental work conducted by authors [16]. Fig. 20 shows stress-strain relationship curves for tested mixtures. 


\begin{tabular}{|c|c|c|c|c|c|}
\hline ઘू & Concrete Mix & $\begin{array}{c}\text { Compressive Strength } \\
\left(f_{c}\right)(\mathrm{MPa})\end{array}$ & MaxStrain & $\begin{array}{c}\text { Modulus of } \\
\text { Elasticity (MPa) }\end{array}$ & $\begin{array}{c}\text { Tensile Strength } \\
(\mathrm{MPa})\end{array}$ \\
\hline B1 & $\mathrm{SCMs} 0 \%+\mathrm{SFs} 0 \%$ & 33.3 & 0.0031 & 28297 & 2.7 \\
\hline B2 & $\mathrm{SCMs} 0 \%+\mathrm{SFs} 1 \%$ & 40.3 & 0.0041 & 30961 & 6.3 \\
\hline B3 & $\mathrm{SCMs} 0 \%+\mathrm{SFs} 2 \%$ & 44.6 & 0.0052 & 33584 & 8.0 \\
\hline B4 & $\mathrm{MS} 10 \%+\mathrm{NS} 1 \%+\mathrm{SFs} 0 \%$ & 48.9 & 0.0031 & 33220 & 4.2 \\
\hline B5 & $\mathrm{MS} 10 \%+\mathrm{NS} 1 \%+\mathrm{SF} 1 \%$ & 53.5 & 0.0045 & 35666 & 7.9 \\
\hline B6 & $\mathrm{MS} 10 \%+\mathrm{NS} 1 \%+\mathrm{SFs} 2 \%$ & 57.3 & 0.0059 & 37540 & 9.3 \\
\hline
\end{tabular}

Table 10: Test results of mechanical properties.

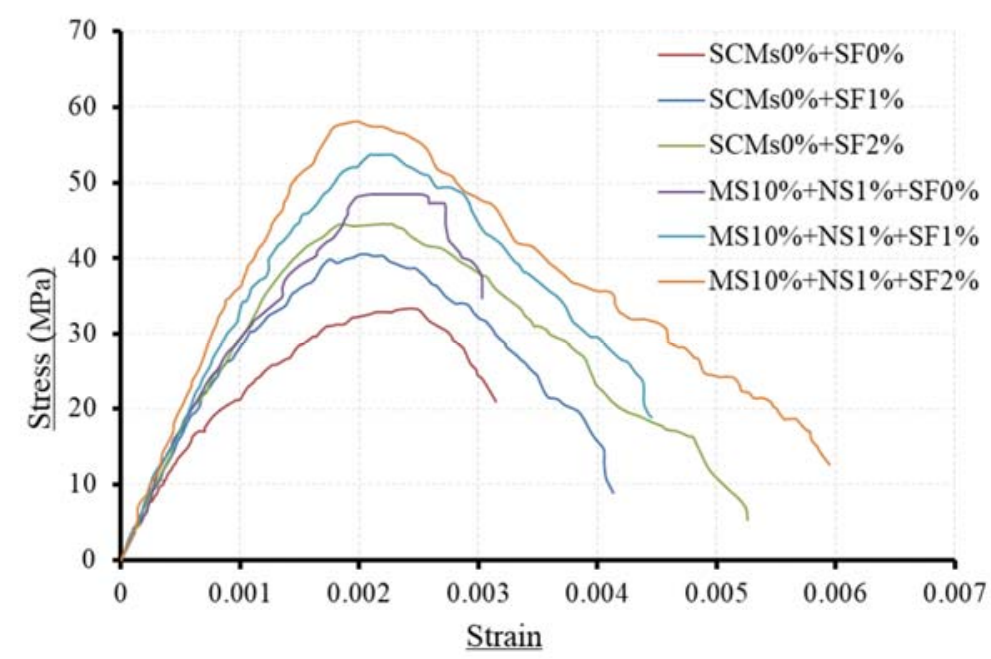

Figure 20: Stress-Strain relationship curves for tested mixtures.

The dynamic mechanical properties of concrete material and steel reinforcement models used in the FE model were calculated according to US-army design approach UFC [4]. Tab. 11 shows the values of DIFs for the far design range.

\begin{tabular}{cccc}
\hline Type of Stress & \multicolumn{2}{c}{ Reinforcement } & \multirow{2}{*}{ Concrete } \\
Bending & Yield & Ultimate & 1.19 \\
Diagonal tension & 1.17 & 1.05 & 1 \\
Direct shear & 1 & -- & 1.1 \\
Bond & 1.1 & 1 & 1 \\
Compression & 1.17 & 1.05 & 1.12 \\
\hline
\end{tabular}

Table 11: DIFs for the far design range of R.C members [4].

As shown in Fig. 21, all beams were reinforced with two $10 \mathrm{~mm}$ diameter deformed reinforcements made of high-grade steel $\left(S t f_{y}=400 / f_{u}=600\right)$, as a main reinforcement and with an $8 \mathrm{~mm}$ diameter non-deformed reinforcement made of mild steel $\left(S t f_{y}=280 / f_{u}=450\right)$, as hooks hangers. Hooks with a diameter of $8 \mathrm{~mm}$ were spaced at a distance of $150 \mathrm{~mm}$ from one another in the major bending plane. Clear cover to reinforcement was maintained at $25 \mathrm{~mm}$. 


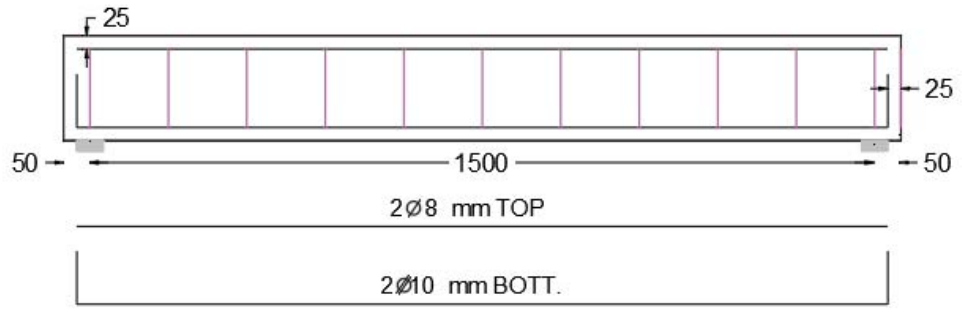

SECTION ELEVATION

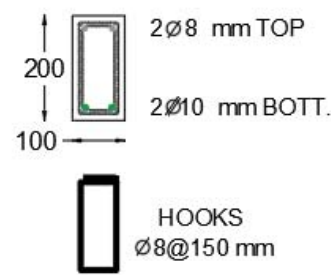

CROSS SECTION

Figure 21: Typical beam reinforcement details.

All R.C beams were exposed to the same air blast pressure as the verified R.C beam (B40-D4). The following results were obtained for each beam model:

- Max Deflection at mid-span.

- Mode of failure.

- Flexural toughness (energy absorption).

\section{Time-Deflection Relationship}

Deflection was measured at mid-span of the tested beams. Time-Deflection curves were developed. Figs. 22 show loaddeflection curves for tested beams, reflecting the effect of adding SMCs and revealing the effect of the presence of steel fibers with different volume fraction content.
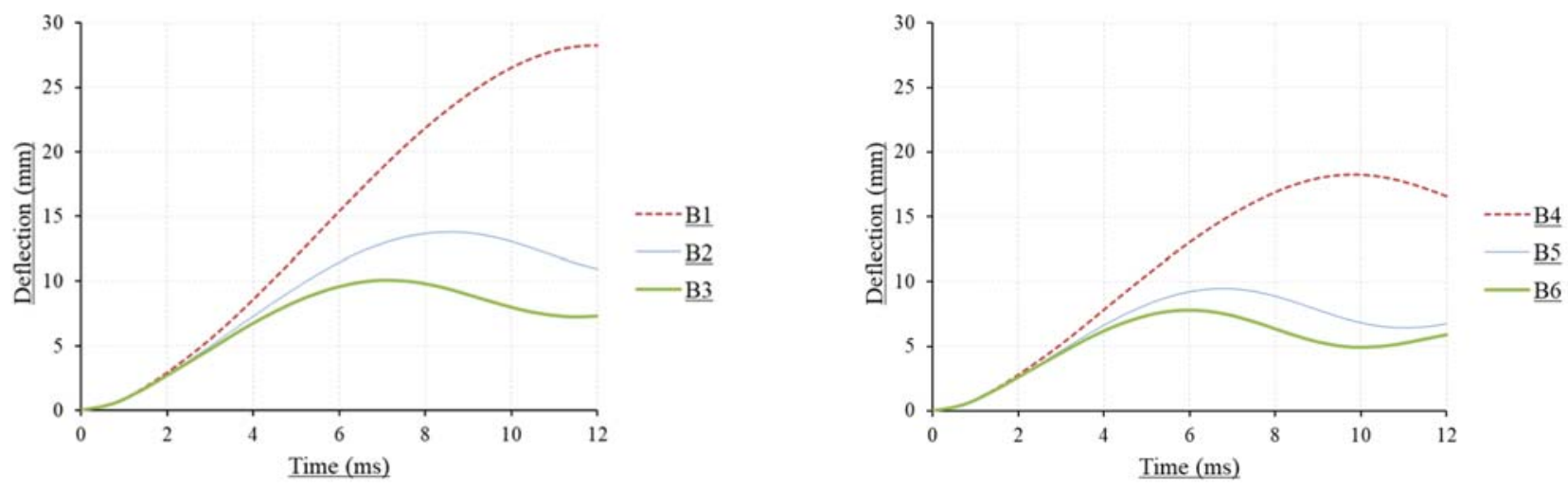

Figures 22: Time-deflection curves for tested beams.

\section{MODES OF FAILURE}

$\mathrm{F}$ igs. 23 and 24 show the tensile stress $S_{11}$ for reinforcement steel and compressive stress $S_{33}$ results for the tested R.C beams obtained by a numerical simulation. Figures show that ductile failure has occurred in all tested beams. The steel reinforcement stress reached yielding stress first then the concrete crushes at the compression zone after experiencing large deflections. Figs. 25 show the failure shapes expected by strain contours and indicates how all beams suffer flexural deformations and bending failure.

\section{Flexural Toughness (Energy Absorption)}

A ductile structure can withstand much more energy (toughness) than a brittle structure of the same static strength. The area under the dynamic reactions-deflection curve (limited up to concrete reaching the maximum compressive stress) was taken into consideration as flexural toughness of tested beams as illustrated in Figs. 26. Tab. 12 shows the max deflection and flexural toughness results of tested beams. Fig. 27 shows the percentage of increase in flexural toughness of tested beams under blast loading in comparison with the compared to reference beam (B1). 

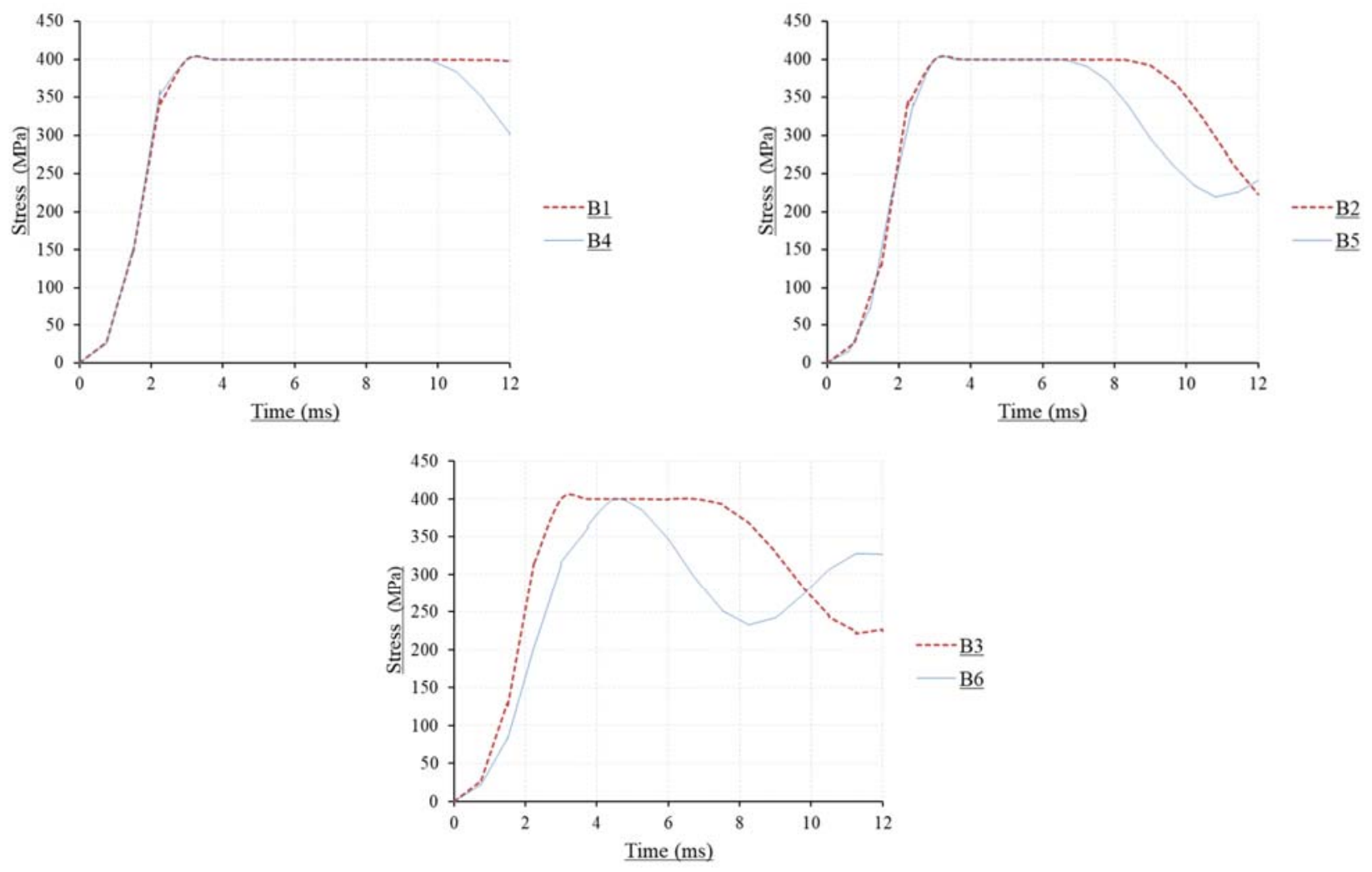

Figures 23: Time-tensile stress $\left(\mathrm{S}_{11}\right)$ curves for tested beams.
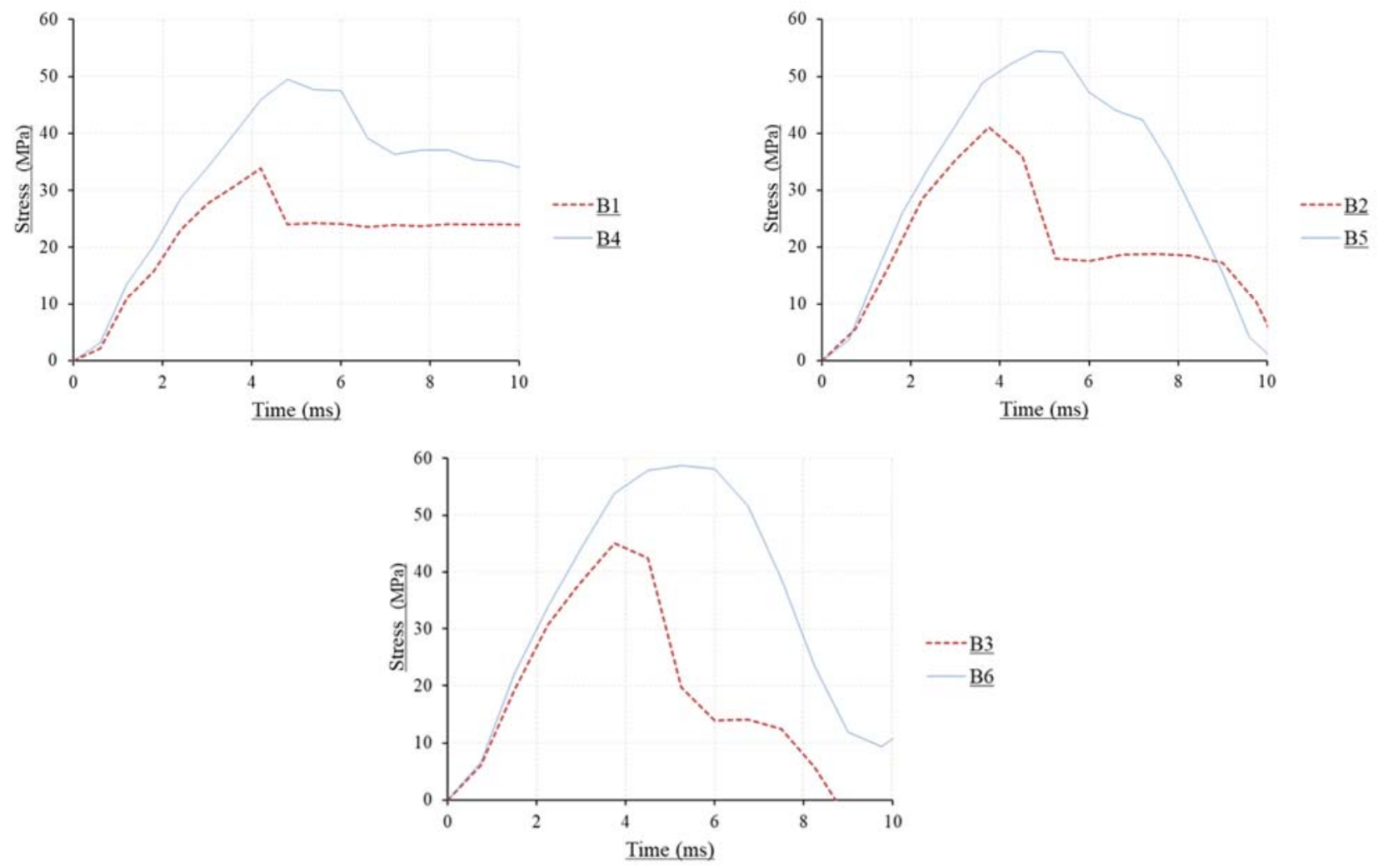

Figures 24: Time-compressive stress $\left(\mathrm{S}_{33}\right)$ curves for tested beams. 


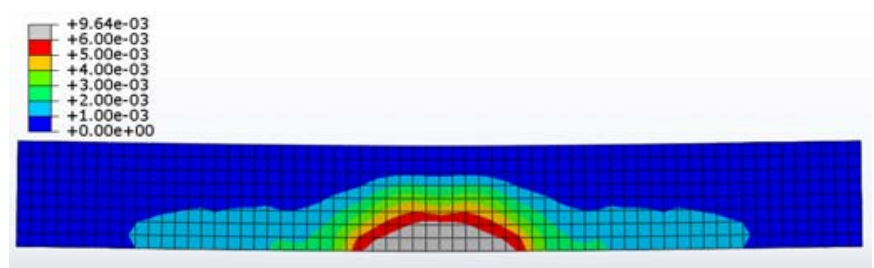

R.C (B1)

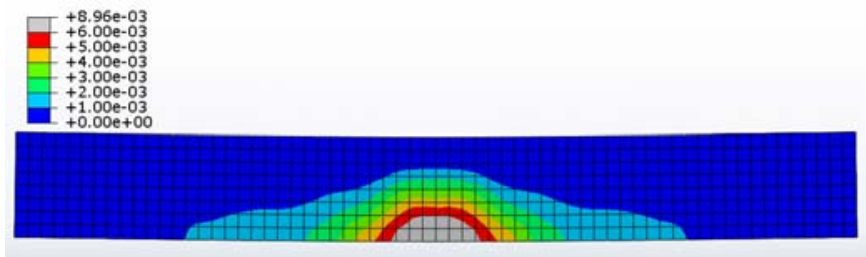

R.C (B2)

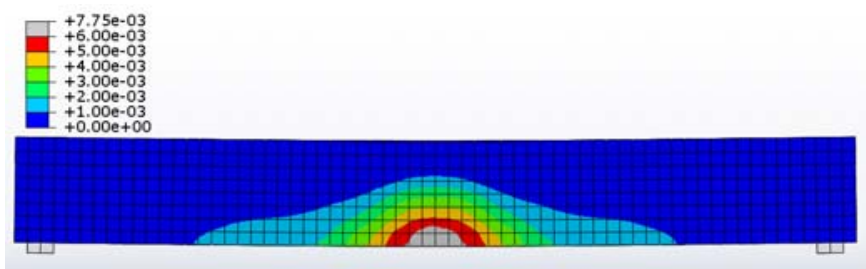

R.C (B3)

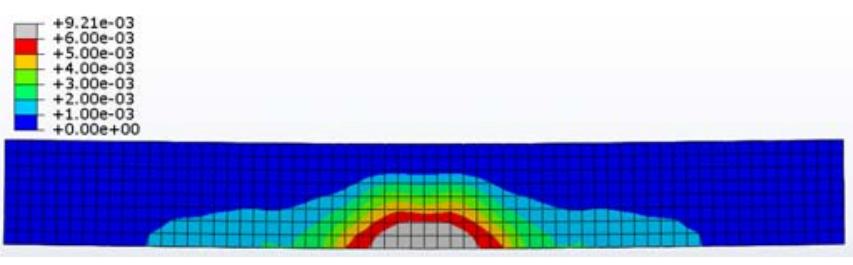

R.C (B4)

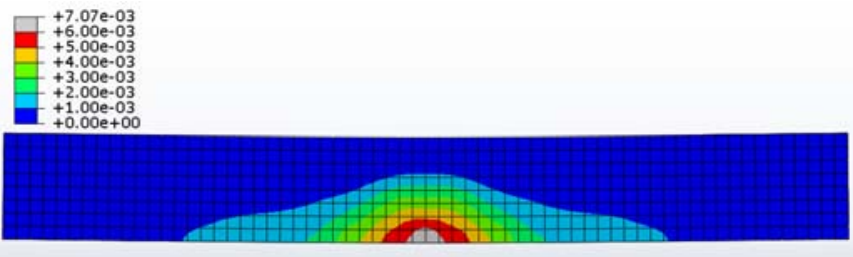

R.C (B5)
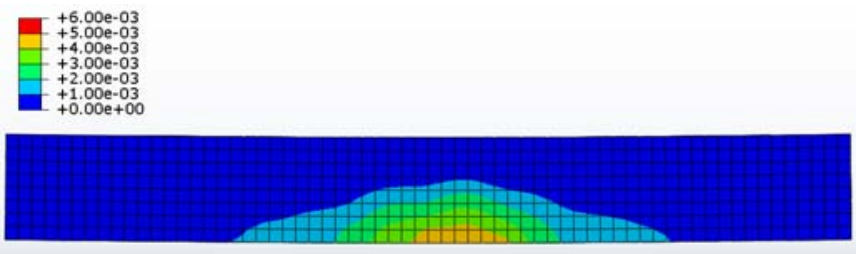

R.C (B6)

Figures 25: Mode of failure for tested beams.

\begin{tabular}{|c|c|c|c|c|}
\hline $\begin{array}{l}\text { Beam } \\
\text { model }\end{array}$ & Concrete Mix & $\begin{array}{l}\text { Failure Time } \\
\qquad(\mathrm{ms})\end{array}$ & $\begin{array}{l}\text { Max. Deflection } \\
(\mathrm{mm})\end{array}$ & $\begin{array}{c}\text { Flexural Toughness } \\
\text { (Joule) }\end{array}$ \\
\hline B1 & $\mathrm{SCMs} \%+\mathrm{SFs} 0 \%$ & 3.6 & 8.5 & 626.2 \\
\hline B2 & $\mathrm{SCMs} 0 \%+\mathrm{SFs} 1 \%$ & 3.75 & 7.7 & 676.4 \\
\hline B3 & $\mathrm{SCMs} 0 \%+\mathrm{SFs} 2 \%$ & 3.75 & 7.5 & 705.3 \\
\hline B4 & $\mathrm{MS} 10 \%+\mathrm{NS} 1 \%+\mathrm{SFs} 0 \%$ & 4.2 & 9.3 & 720.3 \\
\hline B5 & $\mathrm{MS} 10 \%+\mathrm{NS} 1 \%+\mathrm{SF} 1 \%$ & 4.8 & 8.8 & 750.7 \\
\hline B6 & $\mathrm{MS} 10 \%+\mathrm{NS} 1 \%+\mathrm{SF} 2 \%$ & 6 & 8.2 & 774.0 \\
\hline
\end{tabular}

Table 12: Flexural toughness results of tested beams.
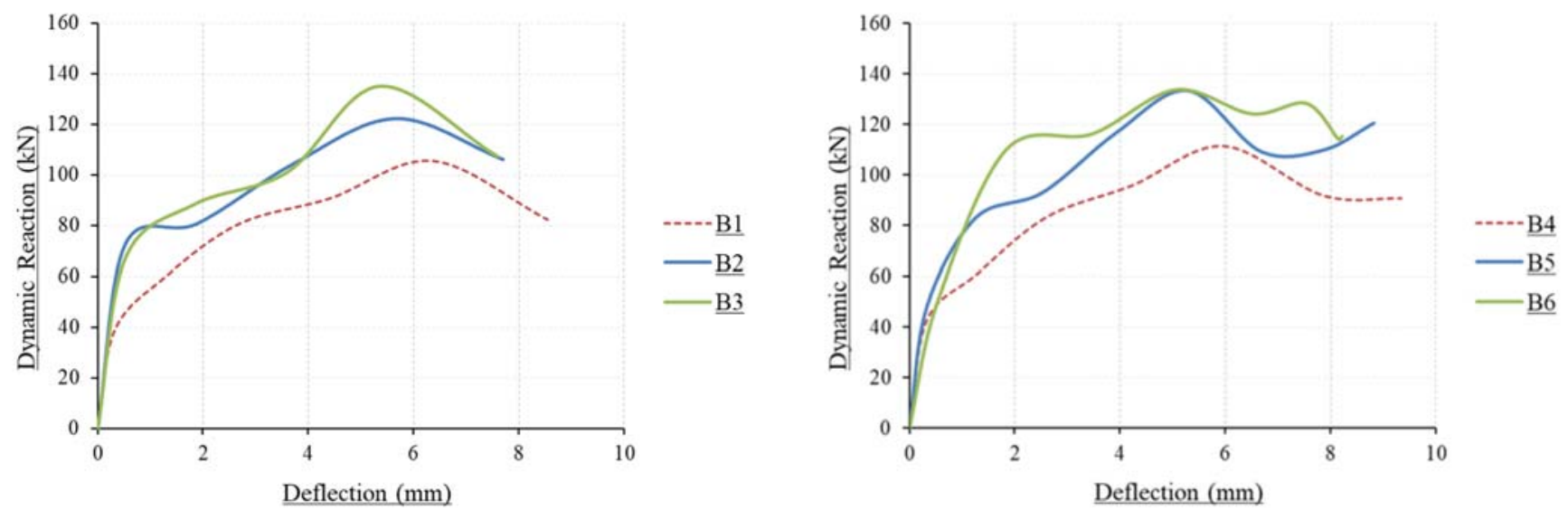

Figures 26: Dynamic reaction-deflection curves (limited) for tested beams. 


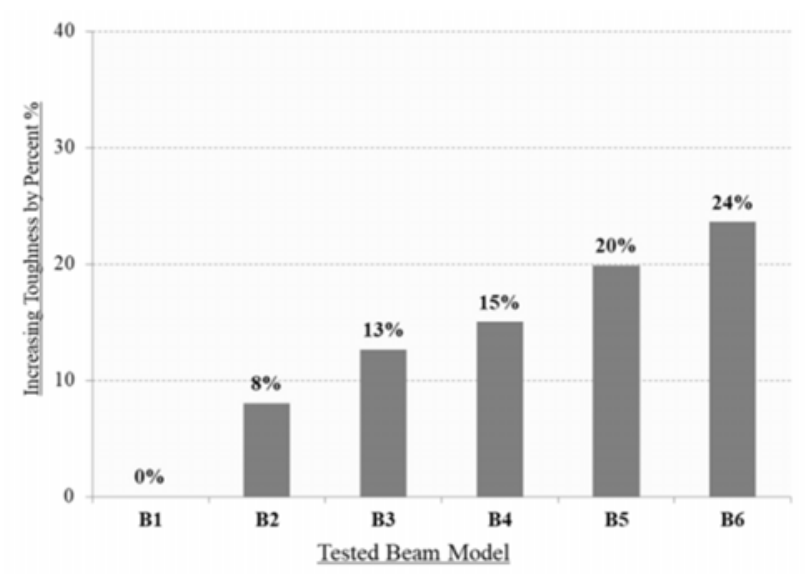

Figure 27: The increase in flexural toughness of R.C beams under blast loading.

\section{PARAMETRIC STUDY}

T

he finite element test program was further extended to investigate the impact of the tensile reinforcement ratio on the behavior of tested R.C beams under blast loading with and without SMCs $(10 \% \mathrm{MS}+1 \% \mathrm{NS})$ in the presence of SFs with different volume fractions.

Three reinforcement ratios were selected. These ratios are $0.5 \%$ (using $2 \mathrm{bars}$ with diameter of $8 \mathrm{~mm}$ ), $0.78 \%$ (using 2 bars with diameter of $10 \mathrm{~mm}$ ), and $1.13 \%$ (using 2 bars with diameter of $12 \mathrm{~mm}$ ). Tab. 13 shows a summary of the calculated results for FE R.C beam models under blast loading. The following results were obtained for each beam model:

- Max deflection at mid-span.

- Flexural toughness values (energy absorption).

\begin{tabular}{|c|c|c|c|c|c|}
\hline Beam model & $\boldsymbol{\mu} \%$ & $\begin{array}{c}\text { Max. } \\
\text { Deflection(mm) }\end{array}$ & $\begin{array}{c}\text { Failure } \\
\text { Time (ms) }\end{array}$ & $\begin{array}{l}\text { Flexural Toughness } \\
\text { (joule) }\end{array}$ & $\begin{array}{l}\text { Failure } \\
\text { Mode }\end{array}$ \\
\hline \multirow{3}{*}{ B1 } & 0.5 & 9.13 & 3.6 & 587 & \multirow{3}{*}{ Ductile Failure } \\
\hline & 0.78 & 8.5 & 3.6 & 626.2 & \\
\hline & 1.13 & 7.88 & 3.6 & 631.7 & \\
\hline \multirow{3}{*}{ B2 } & 0.5 & 8.03 & 3.75 & 627.4 & \multirow{3}{*}{ Ductile Failure } \\
\hline & 0.78 & 7.7 & 3.75 & 676.4 & \\
\hline & 1.13 & 7.08 & 3.75 & 649.1 & \\
\hline \multirow{3}{*}{ B3 } & 0.5 & 7.67 & 3.75 & 644.1 & \multirow{3}{*}{ Ductile Failure } \\
\hline & 0.78 & 7.6 & 3.75 & 705.3 & \\
\hline & 1.13 & 6.52 & 3.75 & 602 & \\
\hline \multirow{3}{*}{ B4 } & 0.5 & 10.7 & 4.2 & 693.88 & \multirow{3}{*}{ Ductile Failure } \\
\hline & 0.78 & 9.35 & 4.2 & 720.3 & \\
\hline & 1.13 & 8.08 & 4.2 & 673.1 & \\
\hline \multirow{3}{*}{ B5 } & 0.5 & 8.72 & 4.2 & 745.6 & \multirow{3}{*}{ Ductile Failure } \\
\hline & 0.78 & 8.21 & 4.8 & 750.7 & \\
\hline & 1.13 & 7.46 & 4.8 & 718 & \\
\hline \multirow{3}{*}{ B6 } & 0.5 & 8.39 & 4.2 & 773.5 & \multirow{3}{*}{ Ductile Failure } \\
\hline & 0.78 & 8.22 & 6 & 774 & \\
\hline & 1.13 & 7.25 & 4.8 & 755.6 & \\
\hline
\end{tabular}

Table 13: Finite element results for R.C beams models using different reinforcement ratios. 
Steel reinforcement ratio $(\mu)$ effect on the time-deflection relationship of tested beams under blast loading

For all tested R.C beams it can be noted that the maximum dynamic reaction capacity of beams increases when the amount of the steel reinforcement increases. In all cases, however, the higher amount of steel reinforcement reduces the deflection of beams. It is noted that concrete with high strength values, for the same reinforcement ratio, leads to an increase in the last beam deflection value and a decrease in the last dynamic reaction value. For the same concrete mixture, the mid-span deflection of the beam decreases as the steel reinforcement ratio increases. Due to the increase of steel reinforcement ratio, the neutral axis's depth increases and as a consequence, the moment of inertia $\mathrm{I}_{\text {effective }}$ will increase, producing a decrease in deflection of R.C beam as shown in Figs. 28. By reducing the amount of longitudinal reinforcement, the ductility of R.C elements will significantly increase in general.
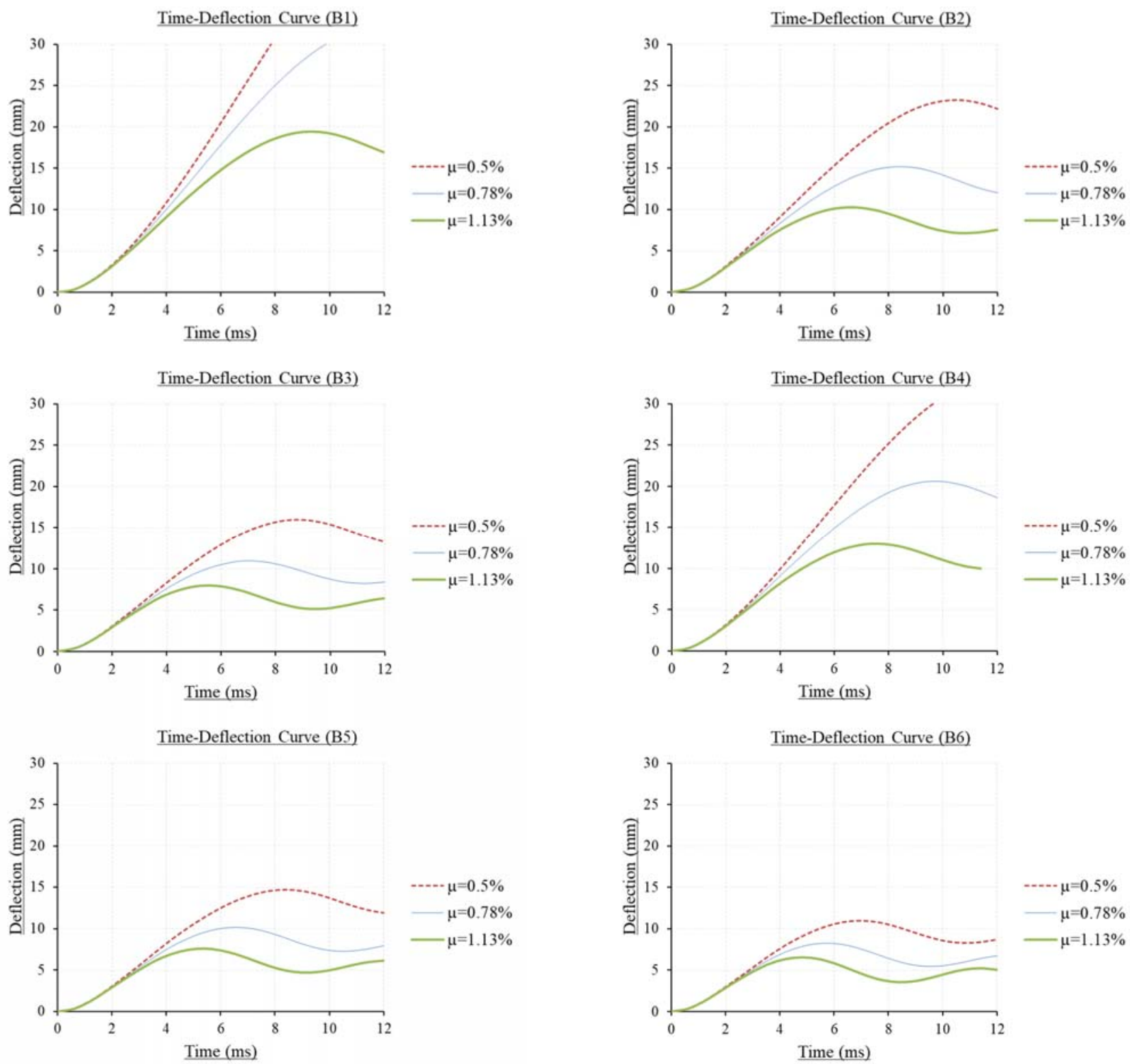

Figures 28: Time-deflection curves for tested beam models using different reinforcement ratios

\section{Steel reinforcement ratio $(\mu)$ effect on the flexural toughness results for tested beams under blast loading}

Figs. 29 show the dynamic reaction-deflection relationship of tested R.C beams with different reinforcement ratios. Flexural toughness results are obtained from the area under the dynamic reactions - deflection curves. It can be observed, 
in the Figs. 29, that beams with ductile behavior carry a lower dynamic reaction force under same load value. Fig. 30 shows the flexural toughness results for tested beams models under blast loading.
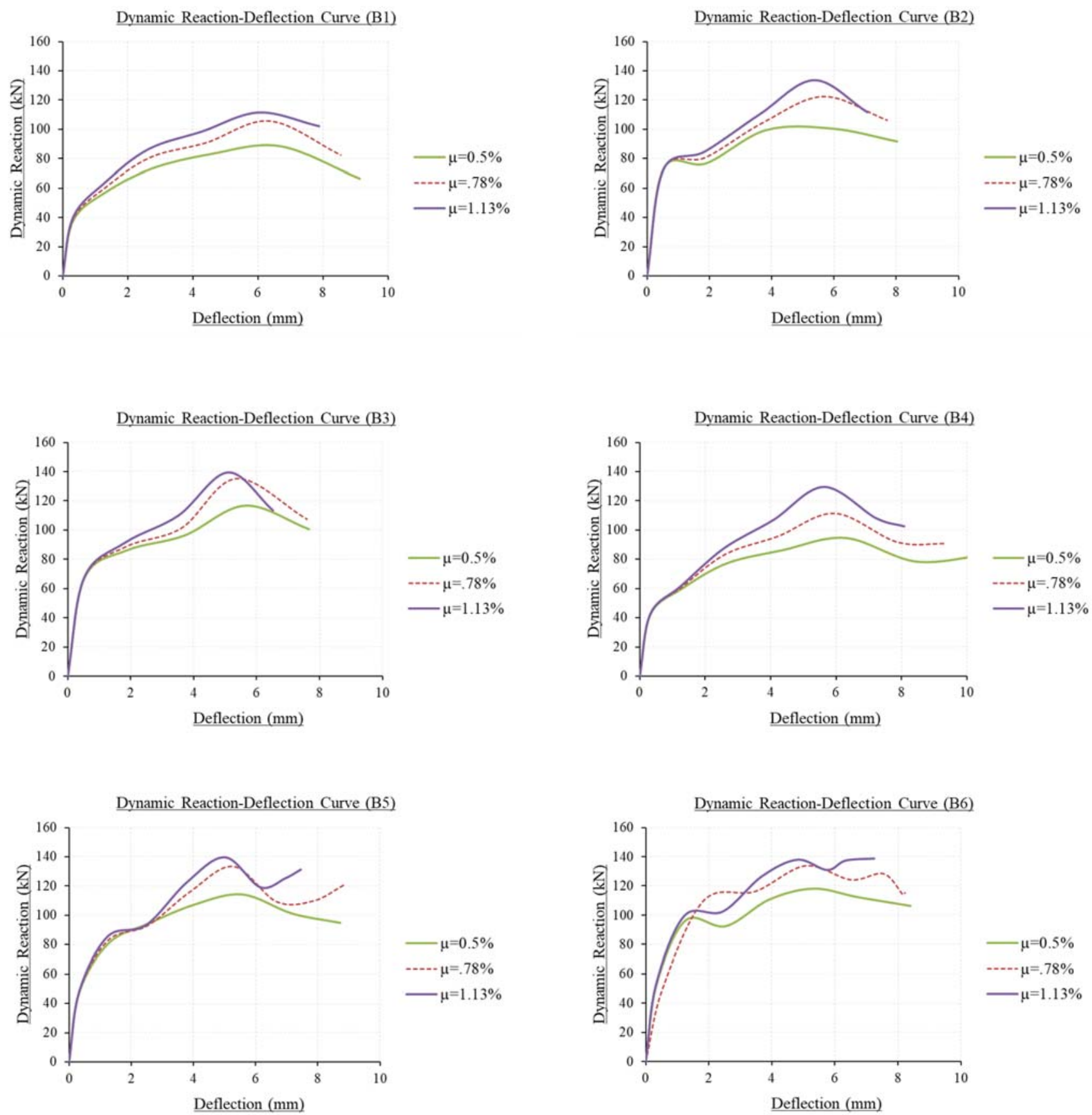

Figures 29: Dynamic reaction-deflection curves for tested beam models using different reinforcement ratios.

When the reinforcement ratio decreases from $0.78 \%$ to $0.5 \%$, the results show an increase in the flexural toughness by $6.9 \%$ and $9.7 \%$ for reinforced concrete beams (B2) and (B3) in comparison with reference beam (B1), reflecting the effect of SFs with volume fractions $1 \%$ and $2 \%$ respectively. For R.C beams with SMCs $(10 \% \mathrm{MS}+1 \% \mathrm{NS})$, the results show an increase in the flexural toughness by $18.2 \%, 27 \%$ and $31.8 \%$ respectively in comparison with (B1). Fig. 31 illustrates the significant increase in the beam ductility within decreasing the tensile reinforcement ratio. 


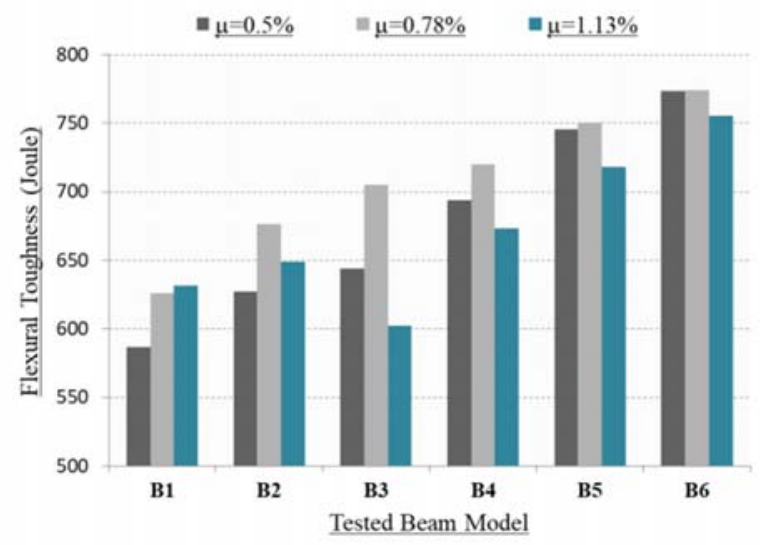

Figure 30: Flexural toughness values for tested beam models using different reinforcement ratios.

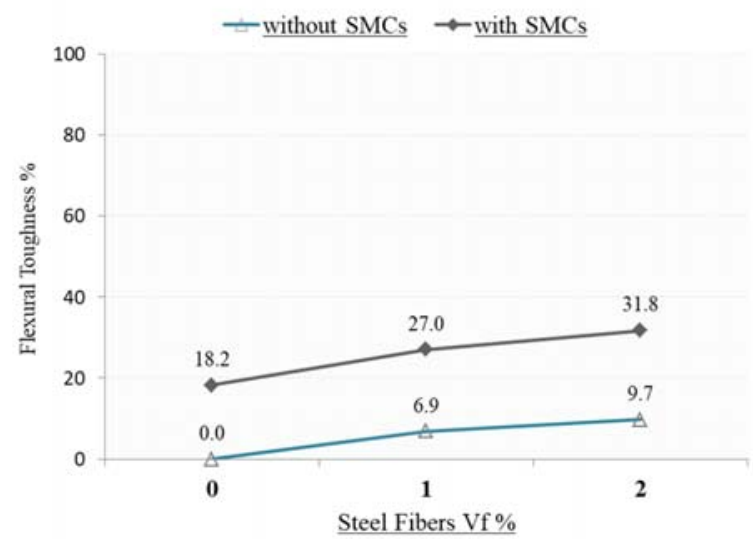

Figure 31: Percentages of increase/decrease in flexural toughness when the reinforcement ratio decreases from $0.78 \%$ to $0.5 \%$.

For the reinforcement ratio of $0.78 \%$, the results show an increase in the flexural toughness by $8 \%$ and $12.6 \%$ for reinforced concrete beams (B2) and (B3) in comparison with reference beam (B1), reflecting the effect of SFs with volume fractions $1 \%$ and $2 \%$ respectively. For R.C beams with SMCs $(10 \% \mathrm{MS}+1 \% \mathrm{NS})$, the results show an increase in the flexural toughness by $15 \%, 19.9 \%$ and $23.6 \%$ respectively in comparison with (B1) as shown in Fig. 32 . It is observed that the percentage of increase in flexural toughness for reinforcement ratio $\boldsymbol{\mu} 0.78 \%$ is smaller than $\boldsymbol{\mu} 0.5 \%$ due to an increase in the moment of inertia ( $\mathrm{I}_{\text {effective}}$ ), leading to a decrease in the deflection of R.C beam and producing a smaller area under dynamic reactions-deflection curves as shown in Figs. 29.

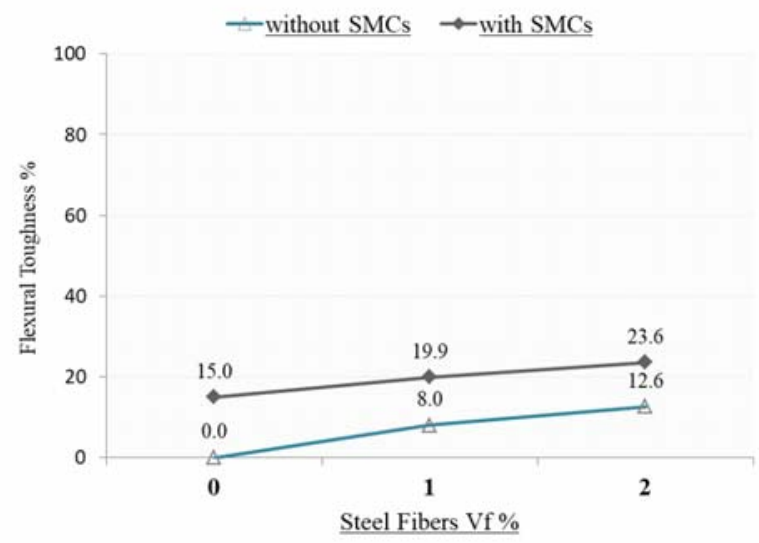

Figure 32: Percentages of increase/decrease in flexural toughness with reinforcement ratio $0.78 \%$ 
When the reinforcement ratio increases from $0.78 \%$ to $1.13 \%$, the results show an increase in the flexural toughness by $2.8 \%$ and a decrease by $4.7 \%$ for reinforced concrete beams (B2) and (B3) in comparison with reference beam (B1), reflecting the effect of SFs with volume fractions $1 \%$ and $2 \%$ respectively as shown in Fig. 33 . Due to the increase of the steel reinforcement ratio $(\mu)$ to be $1.13 \%$, in the presence of SFs with $1 \%$ and $2 \%$ volume fractions which had a high modulus of rupture value on concrete according to the experimental flexural test on tested prisms [16], the neutral axis depth of cross section increases, leading to an increase in the moment of inertia $\mathrm{I}_{\text {effective }}$ and resulting in a reduction in the deflection and flexural toughness capacity of R.C beams as shown in Figs. 29.

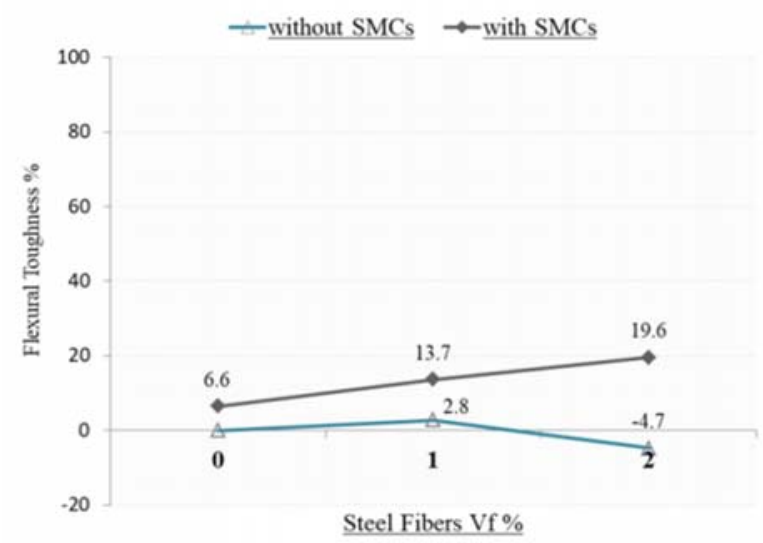

Figure 33: Percentages of increase/decrease in flexural toughness of tested beams when the reinforcement ratio increased from $0.78 \%$ to $1.13 \%$.

R.C beams with SMCs $(10 \% \mathrm{MS}+1 \% \mathrm{NS})$ showed an increase in the flexural toughness by $6.6 \%, 13.7 \%$ and $19.6 \%$ respectively in comparison with (B1). Accordingly, SMCs play an important role in enhancing the flexural toughness of tested beams due to their high compressive strength value in general. For the same steel reinforcement ratio $(\mu)$, the neutral axis depth decreases for concretes with high strength values. This behavior produces an increase in the last beam deflection, leading to an increase in the flexural toughness value of R.C beams. This behavior indicates that combining compressive and flexure characteristics of concrete in case of a high steel reinforcement ratio $(\mu)$ is necessary for reducing the brittle behavior of the R.C structure in general.

\section{CONCLUSION}

A ccording to the numerical analysis of tested R.C beams, The FE model effectively simulates the dynamic responses of displacement and dynamic reaction force time histories. The specific conclusions of the present study can be outlined as follows:

- Improvement in the flexural toughness of the reinforcement ratio $\boldsymbol{\mu} 0.78 \%$ is smaller than that of $\boldsymbol{\mu} 0.5 \%$ due to the increasing moment of inertia ( $\mathrm{I}_{\text {effective}}$ ). Concretes with high strength values lead to an increase in the last beam deflection value, producing a considerable rise in the ductility and flexural toughness of the R.C element.

- When the reinforcement ratio increases from $0.78 \%$ to $1.13 \%$, in the presence of SFs with $0 \%, 1 \%$ and $2 \%$ volumetric fractions, the flexural toughness increases only by $2.8 \%$ and decreases by $4.7 \%$ respectively in comparison with reference beam. The results reflect the negative impact of the high modulus of rupture value of the steel fiber reinforced concrete, and the high ratio of steel reinforcement $\boldsymbol{\mu}$ in R.C beams. By adding SMCs $(10 \% \mathrm{MS}+1 \% \mathrm{NS})$, the flexural toughness increases by $6.6 \%, 13.7 \%$ and $19.6 \%$ respectively in comparison with the reference beam.

- Combination between the compressive and flexural characteristic of concrete is necessary in case of high steel reinforcement ratios to reduce the brittle behavior of the R.C structure element, especially when the R.C elements are exposed to a high strain rate loading due to the added value of (DIFs) for steel reinforcement's mechanical properties, which make the element stiffer than usual.

It is recommended to study the dynamic response of these concrete mixtures experimentally in future works to investigate the exact values of (DIFs) for concrete materials with SCMs in the presence of steel fibers in order to show the enhancement in the response of concrete under blast loads in comparison with the (DIFs) values mentioned in the 
Unified Facilities Criteria UFC [4]. In addition, the plastic hardening of materials should be highly considered in the SDOF calculations. This leads to a real improvement in the response of the element to the blast loads as a result of the enhancement in the ductility and flexural toughness of the R.C structural elements behavior.

\section{REFERENCES}

[1] Baker, W.E., Cox, P.A., Westine, P.S., Kulesz, J.J., Strehlow, R.A. (1983). Explosion hazards and evaluation. Amsterdam; Elsevier.

[2] Biggs, J.M., (1964). Introduction to Structural Dynamics, McGraw-Hill, New York.

[3] Magnusson, J., Hallgren, M. (2000). High Performance Concrete Beams Subjected to Shock Waves from Air Blast, Swedish Defense Research Establishment (FOA), Report R--00-01586-311--SE, Tumba, Sweden.

[4] UFC 3-340-02- Unified Facilities Criteria (UFC) - Structures to Resist the Effects of Accidental Explosions, Department of the Defense, (2008), USA.

[5] FKR, (2011). FortSkydd. Bilaga till FortifikationsverketsKonstruktionsregler FKR, Dnr 4535/2011, Försvarsmakten.

[6] Khizab, B., Sadeghi, A., Hashemi, S., Mehdizadeh, K., Nasseri, H. (2020). Investigation the performance of Dual Systems Moment-Resisting Frame with Steel Plate Shear Wall Subjected to Blast Loading. Journal of Structural and Construction Engineering. DOI: 10.22065/jsce.2020.177510.1820.

[7] Ahmadi, H., Kamran, M. and Tafaroj, N. (2011). Lightweight nano concrete. Journal of Technology and Arts, Construction Engineering Organization, Gilan Province, 52, pp. 8 -13.

[8] Sharaky, I. A., Megahed, F. A., Seleem, M. H. and Badawy, A. M. (2019). The influence of silica fume, nano silica and mixing method on the strength and durability of concrete. SN Applied Sciences, 1(6).

DOI: $10.1007 /$ s42452-019-0621-2.

[9] Barbhuiya, G. H., Moiz, M. A., Hasan, S. D. and Zaheer, M. M. (2020). Effects of the nanosilica addition on cement concrete: A review. Materials Today: Proceedings, 32, pp. 560-566. DOI: 10.1016/j.matpr.2020.02.143.

[10] Taher, M. J., Hassan, M. S. and Al-azawi, Z. M. (2015). Combined effect of silica fume and steel fiber on modulus of elasticity of high performance concrete. Engineering and Technology Journal, 33(4 Part (A) Engineering), 868-876.

[11] Ghazy, A., Bassuoni, M. T., Maguire, E. and O’Loan, M. (2016). Properties of fiber-reinforced mortars incorporating nano-silica. Fibers, 4(1), 6. DOI: 10.3390/fib4010006.

[12] Fawzy, Y. A. E. and Metwally, K. A. (2017). Impact of steel fiber or nano silica on properties of concrete containing various cement types. Life Science Journal, 14(12). DOI: $10.7537 / \mathrm{mars} 1 \mathrm{sj} 141217.06$.

[13] Hasan-Nattaj, F. and Nematzadeh, M. (2017). The effect of forta-ferro and steel fibers on mechanical properties of high-strength concrete with and without silica fume and nano-silica. Construction and Building Materials, 137, pp. 557-572. DOI: 10.1016/j.conbuildmat.2017.01.078.

[14] Sharma, R. and Bansal, P. P. (2019). Efficacy of supplementary cementitious material and hybrid fiber to develop the ultra-high-performance hybrid fiber reinforced concrete. Advances in concrete construction, 8(1), pp. 21-31. DOI: $10.12989 /$ acc.2019.8.1.021.

[15] Murthy, A. R. and Ganesh, P. (2019). Effect of steel fibers and Nano silica on fractions properties of medium strength concrete. Advances in concrete construction, 7(3), pp. 143-150. DOI: 10.12989/acc.2019.7.3.143.

[16] Eisa, A. S., Shehab, H. K., El-Awady, K. A. and Nawar, M. T. (2021). Improving the flexural toughness behavior of RC beams using micro/nano silica and steel fibers. Advances in concrete construction, 11(1), pp. 45-58.

DOI: 10.12989/acc.2021.11.1.045.

[17] Magnusson, J. (2007). Structural Concrete Elements subjected to Air Blast Loading, Licentiate thesis, Royal Institute of Technology, Division of Concrete Structures, Stockholm, Sweden.

[18] Chopra, A. K. (2007). Dynamics of Structures, 3rd Edition. Pearson Education, Inc.

[19] ABAQUS 6.14, Abaqus Analysis User's Guide, Release 14.0 Documentation, (2014).

[20] Zukas, J. A. and Scheffler, D. R. (2000). Practical aspects of numerical simulations of dynamic events: effects of meshing. International Journal of Impact Engineering, 24(9), pp. 925-945. DOI: 10.1016/s0734-743x(00)00012-9.

[21] Malvar, L.J., Crawford, J.E., (1998). Dynamic increase factors for concrete, Department of Defense Explosives Safety Seminar (DDESB), Orlando FL, USA. 